\title{
Review of Cabin Thermal Management for Electrified Passenger Vehicles
}

\section{Lajunen, Antti}

2020

Lajunen , A , Yang , Y \& Emadi , A 2020 , ' Review of Cabin Thermal Management for Electrified Passenger Vehicles ' , IEEE Transactions on Vehicular Technology, vol. 69 , no. 6 , pp. 6025-6040 . https://doi.org/10.1109/TVT.2020.2988468

http://hdl.handle.net/10138/340223

https://doi.org/10.1109/TVT.2020.2988468

unspecified

acceptedVersion

Downloaded from Helda, University of Helsinki institutional repository.

This is an electronic reprint of the original article.

This reprint may differ from the original in pagination and typographic detail.

Please cite the original version. 


\title{
Review of Cabin Thermal Management for Electrified Passenger Vehicles
}

\author{
Antti Lajunen, Senior Member, IEEE, Yinye Yang, Senior Member, IEEE, and Ali Emadi, Fellow, IEEE
}

\begin{abstract}
The technical maturity and rapidly increasing market share of electrified vehicles have given more importance to the cabin thermal management. Efficient thermal management has a key role to maintain adequate electric operating range, protect components from aging and ensure passenger comfort. This research comprehensively reviews the cabin thermal management systems for electrified vehicles. Various vehicle cabin thermal modeling techniques and the key concepts for cabin thermal comfort have been discussed. Different technical and operational solutions of the cabin thermal management in hot and cold climate conditions are evaluated. The recent developments including heat pumps, thermal system control, passive thermal management, and cabin preconditioning to increase thermal management efficiency are analyzed. The results show that increasing amount of research is focusing on improving the thermal efficiency of the individual electrical components and the vehicle level systems. However, new solutions will be required for reducing the cabin thermal load under hot conditions and improving the heating system operational flexibility and efficiency in cold climates.
\end{abstract}

Index Terms - Thermal management; vehicle cabin; cabin heating; cabin cooling; thermal comfort; electrified vehicles

\section{INTRODUCTION}

E LECTRIFICATION of passenger vehicles is considered an effective way of increasing energy efficiency and reduce emissions in transportation $[1,2]$. Consumer acceptance, cost reductions and key technology development have made PHEVs (plug-in hybrid vehicles) and BEVs (battery electric vehicles) more popular every year [3]. In electrified vehicles, thermal system management has a major role to protect electrical components and thus ensure a reliable vehicle operation [4]. Yet, ICE (internal combustion engine) powered vehicles have the major share of vehicle market, and it is estimated that liquid fossil fuels will still be used to power passenger cars for many decades [5]. Thermal management is also an important method to increase the fuel economy of the conventional vehicles by introducing new technologies such as waste heat recovery or phase change materials [6], [7]. The cabin thermal management in ICE powered vehicles is heavily dependent on the engine operation. A typical engine generates waste heat that is used to heat the cabin in cold conditions. Over the years, the size of the passenger vehicle engines have been decreasing and their thermal efficiency have been increasing so

Copyright (c) 2020 IEEE. Personal use of this material is permitted However, permission to use this material for any other purposes must be obtained from the IEEE by sending a request to pubs-permissions@ieee.org. This work was supported by the Wihuri Foundation in Finland.

A. Lajunen is with the Department of Agricultural Sciences, University of Helsinki, FI-00014, Helsinki, Finland (e-mail: antti.lajunen@helsinki.fi) that less excess heat is available. Therefore, a small electric heater is nowadays used especially with small engines to ensure passenger comfort in cold conditions [8]. Thermal management in conventional vehicles can often be challenging to optimize due to the mechanical link from the engine to the auxiliary components. On the other hand, it is more challenging for electrified vehicles to meet cabin thermal requirements. Electric drive systems have high energy efficiency and generate limited amount of waste heat hence, additional electrical heaters are needed. When electric heater or air conditioning is running due to cold or hot ambient conditions, the drive range is impacted by the limited electric energy stored onboard [9]. Therefore, improved thermal management is greatly demanded for advanced electrified vehicles.

Different concepts to improve cabin thermal management in electrified vehicles have been presented in literature. Electrical heaters offer a cost effective solution and have been widely used in all types of vehicles. These are usually PTC (positive temperature coefficient) heaters that are used for the cabin heating [10], and for battery heating in electric vehicles [11]. The PTC heater is typically mounted inside the HVAC (Heating, Ventilation, and Air Conditioning) system after the heat exchanger [12]. Recently, heat pump systems have been introduced because they can reduce significantly the HVAC energy consumption in mildly cold conditions [9], [13]. An automotive heat pump is typically designed based on the traditional air conditioning system [14]. Traditional heat pumps are typically effective in mild ambient conditions because the coefficient of performance (COP) will typically drop in conditions colder than $-15{ }^{\circ} \mathrm{C}$. Nonetheless, recent developments have shown that heat pumps can be useful even in colder than $-30{ }^{\circ} \mathrm{C}[15]$.

Vehicle cabin thermal management is obviously closely connected to the powertrain thermal systems for benefiting any possible excess heat energy and optimizing the vehicle thermal management. The battery system in electrified vehicles is typically operating at the same temperature scale that is desired for cabin conditioning. Therefore, the vehicle thermal management consist of integrated subsystems, which are closely connected to each other. This research does not focus on the battery related thermal management because we have previously published an article focusing on the powertrain

Y. Yang and A. Emadi are with MacAUTO, McMaster University, Hamilton, ON L8P0A6, Canada (e-mail: yangy9@mcmaster.ca; emadi@mcmaster.ca) 
thermal management of electrified vehicles [16] and recent literature provides detail studies focusing on the battery thermal systems.

This research presents an overview of the existing thermal management systems for vehicle cabins and a review of the recent trends for increasing efficiency of cabin thermal systems in electrified passenger vehicles. The research focus is on electrified vehicles including battery electric, hybrid, and plugin hybrid vehicles. First, the system modeling for cabin thermal management is presented following the illustration of the key concepts of the thermal comfort in vehicles. The underlying factors influencing passenger thermal comfort are reviewed and the principles for passenger thermal comfort are evaluated. Then, the air conditioning and cabin heating systems are comprehensively evaluated and different methods analyzed for improving thermal efficiency and cabin pre-conditioning. The recent developments in cabin thermal management are illustrated focusing on heat pumps, thermal energy storages, system control, and passive thermal management. Finally, the conclusion with future projections are presented.

\section{Vehicle CABIN THERMal Modeling}

\section{A. Modeling and Simulation Tools}

CFD simulation tools are often applied for vehicle cabin modeling and simulation to design automotive HVAC systems. Due to the complexity of heat transfer and thermodynamics modeling, high fidelity models usually require high computational effort. Depending on the simulation target, different levels of fidelity of sub-models are often used also with co-simulation methods [17]. In those cases, purpose-built or predefined models offered by commercial simulation software can be considered useful for increasing simulation speed but still getting reliable results. Fig. 1 shows the main heat loads that are usually taken into account in the modelling of a vehicle cabin thermal balance. Some multi-physics simulation software provides specific system models to investigate heat transfer and thermal balance of the vehicle cabin. For instance, LMS AMESim has specific libraries for physical models for complicated components, such as heat

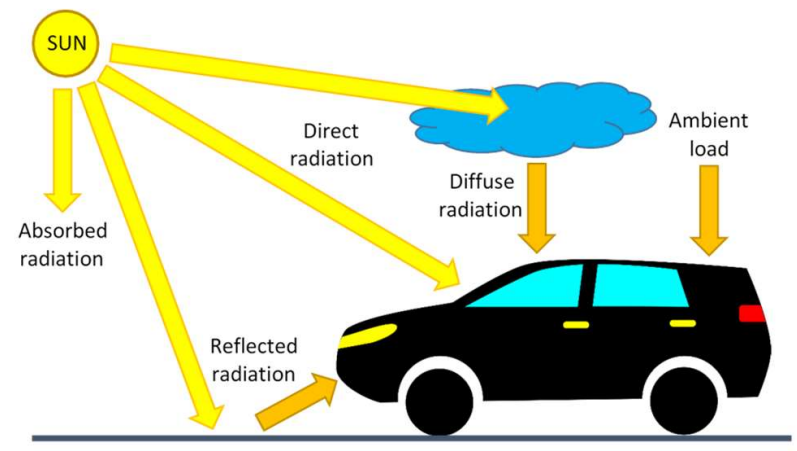

Fig. 1. Cabin external thermal loads.

thermal-hydraulics and two-phase flows that allows building exchangers, and for complex systems e.g. air conditioning or heat pump [9]. The characteristics of the LMS AMESim predefined cabin thermal model were explained by Broglia et al. [18]. Different simulation software have been applied in the system modeling of vehicle cabin thermal balance: MATLAB SimDriveline [19], AMESim [9], [18], Modelica [20], MATLAB/Simulink [21]. More often nowadays vehicle models are developed in numerical simulation platforms such as MATLAB. They offer a practical and flexible environment for fast calculations and tools for the integration with other modeling software [22]. The cabin model in AMESim software is presented in Fig. 2. It consist of elements that describe the thermodynamic properties of the main components. The heat transfer is calculated between the cabin components (the windshield, side windows, rear window, side panels and roof) and surrounding environment. Five different material options are predefined for the components including glass, plastic, metal, foam and fabric.

\section{B. Simulation Studies}

The overall distribution of temperature was predicted by a coarse 3-D model, which was based on a simplified cabin geometry. The model was also used to simulate operation of air conditioning under transient hot-soak and cool-down of a cabin. [23]. A CFD simulation model of an SUV cabin was developed

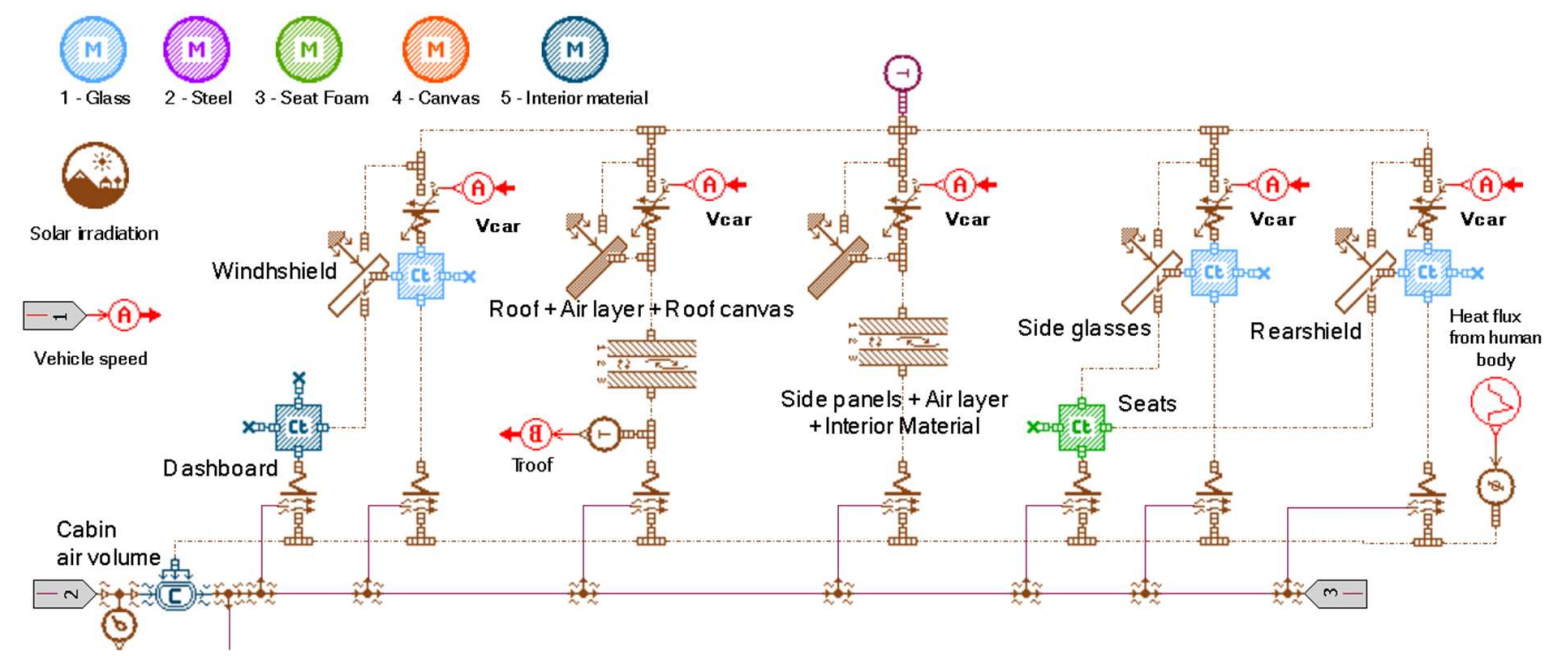

Fig. 2. Cabin thermal balance model in AMESim software. 
by Ghosh et al. [24] for the characterization of the interior thermal environment and for evaluating the fluid-thermal environment in accurate manner around the occupants. The presented research focused on HVAC system using a spot cooling and it was analytically found that under ideal conditions of nozzle locations and airflow delivery, it was possible to achieve the same conditions with $30-50 \%$ lower airflow per person [24].

Coupling of 3D airflow simulation and 1D fluid node networks was applied for heat transfer of vehicle cabin in [25]. Based on the research results, the method enables simulating long process of cabin heat up and cool down as well as resolving temperature differences inside the cabin. A lumped parameter vehicle cabin model based on heat balance was developed by Fayazbakhsh and Bahrami [26]. According to the simulations in various driving cycles, solar radiation and ventilation have important influence on the variation of cabin temperature whereas some loads such as the engine block, engine exhaust system, and reflected radiation can be often considered unimportant. Similar conclusions were made by TorregrosaJaime et al. [27] as they developed and validated a thermal model with lumped-parameters for a passenger compartment. They also found out that a decrease the glazing transmissivity by 0.2 could lead a reduction of cooling capacity by $3.3 \%$. In another study, the dynamic thermal behavior of a cabin conditions was investigated by a transient thermal model [28]. The model was used for the investigation of using saturation cycle instead of vapor compression cycle in the $\mathrm{A} / \mathrm{C}$ system. The saturation cycle showed almost $24 \%$ higher efficiency and could reduce the power consumption by $19.3 \%$. The characteristics of heat transfer in a vehicle cabin under nonisothermal conditions were investigated with a scale model when using air conditioning [29]. The same model was also used for determination of the temperature field inside the cabin in order to develop HVAC control [30]. Nielsen et al. recently developed a detailed simulation model for the vehicle interior climate for predicting the total energy use [31]. The research results showed that the model worked in various conditions and had good accuracy.

The studied literature shows that modeling and simulation are powerful tools for the development of thermal systems and the evaluation of system efficiencies. These tools are providing versatile methods of simulation and they are going to be needed in the development of optimal designs, and especially when taking into account the vehicle driving cycle and operating routes. The resulting thermal and energy efficiency of electrified vehicles is often dependent on the vehicle use patterns and charging schedule.

\section{THermal COMFORT}

\section{A. Background}

The importance of driver and passenger thermal comfort has been increasing alongside with the development of infotainment systems and more time spent in driving. Cabin thermal comfort has an important influence on driver's concentration and alertness [32]. Many different factors impact on thermal comfort, indoor air quality, and in general to human thermal sensation [33], [34]. In a typical passenger vehicle, thermal comfort is controlled by the cabin temperature, which tend to consume quite a lot of energy and this is a particular concern especially for electric vehicles [35]. The cabin climate can be controlled by the HVAC or climate system. After safety functions, such as defogging and de-icing the windshield and windows, the climate control system ensures the comfort of the driver and passengers. The comfortable temperature for humans is typically between $21^{\circ} \mathrm{C}$ and $27^{\circ} \mathrm{C}$ but higher temperatures can also be acceptable with lower humidity. Because warm air can hold more moisture than cold air, dehumidification is an important function of vehicle climate systems to increase thermal comfort in warm conditions. The American Society of Heating and Air-Conditioning Engineers (ASHAE) map of thermal comfort is often used to define the comfortable temperature set points [36]. A typical thermal condition target of vehicle cabin is between $23{ }^{\circ} \mathrm{C}$ and $27{ }^{\circ} \mathrm{C}$ with relative humidity of $50 \%$ [37]. Because humans are relatively sensitive to heat, or the lack of it, in addition to thermal comfort based on temperature, the physiological thermal sensation can be considered equally important. This is even more important in vehicles because the cabin climate typically changes considerable in space and time, while ventilation generates nonuniform air velocity and temperature distribution [38]. Another challenge is the fact that people have different physiological and psychological sensations on thermal comfort [39]. In summary, several factors influence on thermal comfort in vehicles as described in Fig. 3. [40].

Specific thermal comfort indices have been developed and proposed over the years. The most well-known indices are the predicted mean vote (PMV) and the associated predicted percentage of dissatisfied (PPD) introduced by Fanger more than three decades ago [41]. The dependence of PMV and PPD is presented in Fig. 4. Since PMV is developed for homogenous conditions, it is difficult to get accurate predictions for cabin thermal comfort because of the non-homogenous conditions [42]. Nowadays there are different standards that propose methods to evaluate and analyze thermal comfort in the vehicle cabin environment, for instance, EN ISO 14505 [43] and the American ASHRAE - 55 [44].

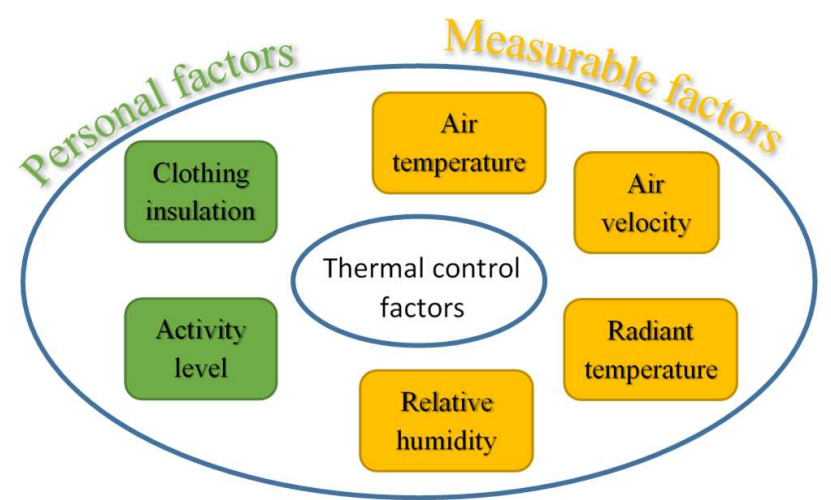

Fig. 3. Typically used factors for determining thermal comfort in vehicles (Data from [40]). 


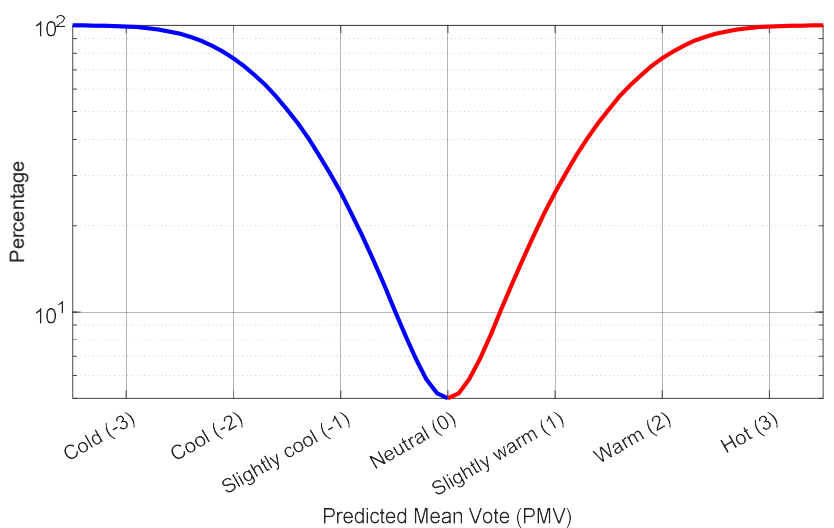

Fig. 4. The dependence between PPD persons and the predicted mean vote (Data from [42]).

\section{B. Developments in Thermal Comfort}

New evaluation method has been proposed to predict local thermal sensations and whole-body thermal comfort by using human thermoregulation model [34]. The method includes quantitative evaluations of thermal sensation and comfort based on the local standard new effective temperature (SET) [45]. In addition to the frequently used PMV and PPD thermal comfort indices, DTS (dynamic thermal sensation) and TS (thermal sensation) are also useful especially when evaluating human thermal comfort by a manikin model [38], [46]. A comfort driven cabin HVAC system was investigated in a recent study by measuring temperatures in several locations in close proximity to passenger [47]. This detailed temperature information was used for investigating personalized and comfort driven HVAC control. Thermal comfort is an outcome of subjective perception and heat transfer alone is insufficient for describing thermal comfort in a vehicle cabin.

Different types of simulation models have been developed to investigate and evaluate the human thermal comfort in vehicle cabins. These models often include some type of CFD model for the cabin that is verified by experimental measurements. Jeffers et al. developed a human physiology model for evaluating the influence on occupant thermal comfort [48]. The model included a virtual manikin, which enabled human thermal comfort analysis using the human physiology model. A thermal/physical model was also used for the simulation of thermal interactions between driver and seats [49]. Thermal comfort was analyzed based on the heat transfer between the human body and cabin environment, while body temperature was calculated by using Fanger's empirical correlation by averaging local thermal sensation. The research concluded that heated seats provided fast thermal comfort in cold conditions and ventilated seats also increased comfort. Because seats are in direct contact to passenger, they have an important role to improve thermal comfort in vehicle cabins. Thermal comfort can be improved by e.g. choosing seat cover materials that have low resistance to the passage of perspiration, using ventilated seats, and using seat heating [32]. The advantage of seat thermal management is the ability to provide fast thermal comfort for passengers despite of the initial conditions.
Passenger thermal comfort was predicted by using the body's energy balance based on manikin model in [38]. The influences of different ambient parameters and conditions were evaluated and the research results strongly indicated that accurate predictions of temperature distributions in the cabin were crucial to the success of numerical simulations. Similar study was presented by Chen et al. [50] as they predicted thermal sensation and comfort of occupants in crossover vehicle by a virtual thermal comfort engineering (VTCE) tool. Alahmer et al. presented an approach to analyze cabin thermal comfort based on thermography and discrete thermocouple network [51]. The research also included an analysis of relative humidity impact on thermal comfort during cooling and heating processes. Furthermore, the HVAC system also controls the cabin air quality, which has an important impact on the passenger comfort in general. Thermal efficiency of cooling and heating can be improved by the recirculation of the cabin air whereas fresh air is used for maintaining adequate air quality. $\mathrm{CO}_{2}$ concentration is one important measure of cabin air quality and it is recommended not to exceed $1200 \mathrm{ppm}$ [36], [52]. $\mathrm{CO}_{2}$ concentration is also dependent on vehicle speed and number of occupants. In a recent study, a prediction equation model was developed to evaluate $\mathrm{CO}_{2}$ concentrations [33]. The ventilation mode and mass flow were major factors influencing $\mathrm{CO}_{2}$ concentration in vehicle cabins.

Over the years, thermal comfort have been steadily increasing in passenger vehicles due to the modern HVAC and control systems. Because people are spending more time in driving or in traffic, they need to have thermally comfortable traveling space. As vehicles are getting larger, conditioning the entire cabin to a comfortable temperature and humidity requires more energy, which is not desirable. Therefore, local solutions such as seat specific technologies and zonal conditioning are considered as effective solutions to be further developed.

\section{AIR CONDITIONING}

\section{A. System Overview}

Cooling of a vehicle cabin is done by an air conditioning $(\mathrm{A} / \mathrm{C})$ system, which uses a refrigerant in the vapor compression cycle (VCC) to extract heat from the cabin ventilation air. There are two basic types for air conditioning systems: 1) Expansion valve type with a receiver-drier, and 2) Orifice tube system with an accumulator. An expansion valve type A/C system includes a compressor, condenser with a fan, drier/receiver, expansion valve, and evaporator as illustrated in Fig. 5. The other basic system have an orifice tube instead of an expansive valve. This system does not have a drier/receiver but an accumulator prior to the compressor. The remaining liquid after evaporator is boiled back to vapor.

In recent years, internal heat exchanger (IHX) type compression cycles have become more common to increase $\mathrm{A} / \mathrm{C}$ efficiency. An internal energy recovery is done when at the evaporator outlet the low temperature gas cools down the liquid refrigerant coming from the outlet of the condenser [53]. Another system solution is the dual or secondary loop solution that reduces the refrigerant quantity and the dimension of the 

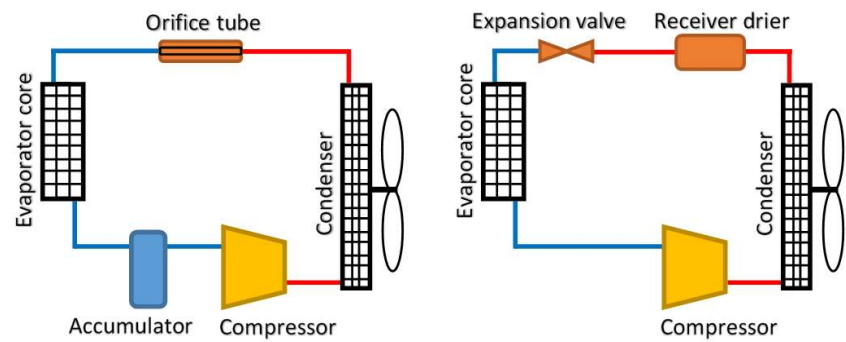

Fig. 5. Two basic types of air conditioning systems.

$\mathrm{A} / \mathrm{C}$ refrigerant loop [54]. This solution can also diminish the required space at the front of the vehicle and improve the security with the new refrigerant usage such as HFO-1234yf. The cabin air ventilation and dehumidification can be managed with an air cooler by using a secondary loop that uses the $\mathrm{A} / \mathrm{C}$ refrigerant for the water refrigeration [55]. Cabin air-cooling is sometimes used to cool passively the traction battery in warm ambient conditions. This was typical applied in early HEV and BEV battery packs main reason being the cost, mass, and space [56]. In conventional vehicles, the ICE powers directly the A/C compressor. In electric vehicles, the compressor is powered by an electric motor whereas in hybrid vehicles, the compressor can be operated either by the belt from the engine or by an integrated electric motor. Many types of compressors are available while the most common compressor types in automotive applications are reciprocating piston, rotary scroll and vane type compressors.

Air dehumidification is a necessary process in cabin cooling. In this process, the air is first cooled down to the dew point and continued cooled until the desired humidity is reached. Because dehumidification requires energy, different solutions have been developed for reducing energy consumption. One solution is to use a desiccant cycle where the air dehumidification is done without the need to be cooled below the dew point [57].

\section{B. Refrigerants}

Regarding refrigerants, different types can be used in the vapor compression cycle [58]. The most common refrigerant is HFC-134a. However, refrigerants such as HFO-1234yf and R744 $\left(\mathrm{CO}_{2}\right)$ are tested and considered for automotive use in order to reduce environmental impacts. The currently used halogenated refrigerants have excellent thermodynamic and chemical properties, whereas disadvantages associated with hydrocarbons are their possible flammability and other safety concerns [59]. HFO-1234yf was recently studied as drop-in replacement for HFC-134a and many of the car manufacturers have chosen the refrigerant HFO-1234yf in order to replace the HFC-134a, which has much higher Global Warming Potential (GWP) [60]. Research results showed that the heat transfer coefficient in the refrigerant side to be $18-21 \%$ lower for the HFO-1234yf. The experimental measurements also indicated a slightly lower performance in terms of cooling capacity and COP (Coefficient of Performance). However, the compressor pressure ratio and discharge temperature were lower which could extend compressor life. Changing the refrigerant e.g. to R744 requires a new system design and different types of components [61]. In European Union, starting from January $1^{\text {st }}$
2017, no EC (European Community) or national-type approval has been granted for vehicles having an air conditioning system which refrigerant contains fluorinated greenhouse gases and a GWP value higher than 150 [62]. The thermodynamic and chemical properties of automotive refrigerants are presented in Table 1.

\section{Energy Efficiency}

Since air conditioning can increase fuel consumption more than $35 \%$ in conventional vehicles [50] and the operating range of electric vehicles can be reduced more than $50 \%$ in hot ambient conditions [63], it is important to increase the system energy efficiency. Three main methods have been recognized: 1) optimize system efficiency, 2) advanced window glazing, and 3) local cooling strategies [50]. The improvement of A/C system efficiency and alternative refrigerants have been the focus area in recent research. Khayyam et al. focused on the energy management system of the air conditioning in conventional vehicles to minimize fuel consumption. Under various conditions, they decided to dynamically adjust the cabin blower speed and control the air nozzles opening [64], [65]. The simulation results indicated $14 \%$ increase in system efficiency when proper management of the opening and closing of the fresh air and air recirculation gates was found [65]. In another study by Khayyam [66], an adaptive intelligent and predictive control was developed based on fuzzy logic and neural network for better air quality and energy efficiency. The look-ahead control strategy used a prediction of road power demands and simulations showed around $1 \%$ reduction of energy consumption.

\section{Alternative Cooling Systems}

Alternative cooling systems were studied by Javani et al. namely steam ejector and absorption systems that can be used for waste heat recovery [67]. The study focused on the cabin cooling of electric vehicles and HEVs by using both exergy and energy analyses for ejector and absorption refrigeration cycles. The research results showed that a sufficient cooling load could not be produced in the evaporator by using the waste heat that was recovered from the battery pack during the electric driving mode. Alternatively, the heat from the exhaust gases of engine in HEVs could generate over $7 \mathrm{~kW}$ cooling capacity.

TABLE 1: COMPARISON OF DIFFERENT AUTOMOTIVE REFRIGERANTS (DATA FROM [68], [69])

\begin{tabular}{lllll} 
Refrigerant & R134a & R1234yf & R152a & R744 \\
\hline Ozone Depletion Potential & 0 & 0 & 0 & 0 \\
Global Warming Potential & 1,430 & 4 & 140 & 1 \\
Molar mass $(\mathrm{kg} / \mathrm{kmol})$ & 102.3 & 114 & 66.1 & 44.0 \\
Normal Boiling Point $\left({ }^{\circ} \mathrm{C}\right)$ & -26.1 & -30.0 & -24.0 & -78.0 \\
Critical temperature $\left({ }^{\circ} \mathrm{C}\right)$ & 101.1 & 94.7 & 113.3 & 31.0 \\
Critical pressure $(\mathrm{kPa})$ & 4,059 & 3,382 & 4,520 & 7,380 \\
Vapor specific heat @ $5^{\circ} \mathrm{C}$ & 0.921 & 0.949 & 1.187 & 0.850 \\
$(\mathrm{~kJ} / \mathrm{kg}-\mathrm{K})$ & & & & \\
Latent Heat @ $5^{\circ} \mathrm{C}(\mathrm{kJ} / \mathrm{kg})$ & 194.7 & 160.7 & 301.4 & 234.5 \\
Liquid density @ $50^{\circ} \mathrm{C}$ & 1,102 & 989.9 & 830.5 & 762 \\
$\left(\mathrm{~kg} / \mathrm{m}^{3}\right)$ & & & & \\
Vapor density @ $10^{\circ} \mathrm{C}$ & 17.2 & 20.8 & 9.9 & 1.833 \\
$\left(\mathrm{~kg} / \mathrm{m}^{3}\right)$ & & & & \\
\hline
\end{tabular}


In a recent study, a phase change material (PCM) cold storage heat exchanger was developed into the evaporator of the $\mathrm{A} / \mathrm{C}$ system [70]. This type of cold storage is an effective solution especially for the stop-and-go-type of hybrid vehicles to provide cabin cooling during engine standby. The key parameters for a cold storage are refrigerant circuit configuration, and fin height density. These parameters can be modified for an optimal design. However, the research results demonstrated that the volume rate of the incoming air and air temperature had an important effect on the system performance of the cold storage [70].

Vehicle simulations aided by advanced thermal manikin measurement were used for evaluating zonal cooling configuration, which resulted in range improvements of the electric vehicle between $6 \%$ and $15 \%$ depending on the driving cycle [63]. The range could be further increased by incorporating the zonal cooling and thermal load reduction strategies to form a combined cooling configuration. On the other hand, solar irradiance may have a significant effect on the cabin temperature in hot climates [71], [72]. The heating effect of solar irradiance can be reduced by different window material and technologies such as solar protection film [73], [74]. An outdoor thermal soak test was carried out to determine the reduction in temperatures by using solar control PVB (polyvinyl butyral) windshield [75]. The analysis concluded that around $4 \%$ reduction in air conditioning power capacity could be achieved and EV range increased from $0.7 \%$ to $1.5 \%$ depending on the driving cycle. The glass glazing typically has a constant transmissivity although better solution would be to have variable transmissivity being higher in cold weather and lower in hot weather conditions by using for example photovoltachromic or electrochromic glazing technologies. In general, reducing the cabin heat load coming from the solar radiation would be an efficient way of reducing the required cooling capacity for the cabin.

\section{CABIN HEATING}

\section{A. System Overview}

In cold ambient temperatures, the vehicle cabin needs to be heated to ensure passenger comfort. Based on a validated simulation model, the cabin heating may reduce the driving range of an electric vehicle up to $50 \%$ in cold climatic conditions [76]. A cabin heating and ventilation system is also important for defrosting and defogging the windshield to insure operating safety with adequate visibility [77], [78]. In conventional vehicles, the ICE typically produces enough waste heat, which can be extracted from the engine cooling circuit by a heat exchanger (heater core) to heat up the cabin. The modern diesel engines are energy efficient and produce less waste heat than before therefore additional electric heaters are used for faster engine warm-up and better passenger comfort [12].

In hybrid and electric vehicles, electric heaters have to be used because there is not enough waste heat available either from the engine or from the powertrain. PTC heaters are usually used as the electric heaters in vehicle applications. Low voltage electric heaters have heating capacity up to $1 \mathrm{~kW}$, which is usually enough for auxiliary heaters used with engines. In hybrid and electric vehicles, high voltage heaters with much higher heating capacity is required, typically between 5 and 7 $\mathrm{kW}[10]$. An electric heater can be integrated into the cooling system to heat the coolant medium while the cabin heat is extracted from a heat exchanger. Alternatively, cabin PTC heater can be installed directly into the cabin ventilation tunnel though it is not a popular approach because of the high voltage. Typical characteristics for PTC heaters include thermal selfregulation, energy efficiency, high safety standard (no glowing parts), rapid thermal response time, wide temperature range, long service life, and compact design [79]. The self-regulation resistance of PTC heaters have been seen as an enhanced and important safety feature. The cabin heating demand for a midsize electric vehicle was investigated in a recent study by a simulation model with a dedicated cabin thermal model [9]. The average heat flows from the cabin to the ambient environment were calculated for different cabin elements in different operating temperatures as shown in Fig. 6. The simulation results show that the heat flow through the sides, thus the doors, is rapidly increasing in cold and hot temperatures.

Cabin heating is a major challenge especially for battery electric vehicles because heating with battery energy can reduce significantly the operating range [9]. According to Kambly and Bradley, the cabin heating is considered as a technical bottleneck for electric vehicles in the cold regions [37]. The maximum driving range of today's midsize EV is about 250 to $300 \mathrm{~km}$ and many studies demonstrate that the range decreases about $40-50 \%$ by the operation of the cabin electric heating [9], [48]. The challenge is to improve the heating system efficiency and minimize the energy consumption, having only limited amount of heat available.

\section{B. Energy Efficiency}

Different solutions have been developed and introduced to improve the cabin heating efficiency [80]. In the literature, fuel cell systems [81] and fuel heaters [82], [83] have been proposed and investigated as heat sources in electric vehicles. Fuel heaters provide a very effective solution for the vehicle heating but the produced emissions are problematic to the otherwise zero emission vehicles [82], though it is possible to use more environmentally friendly fuels such as biodiesel [83].

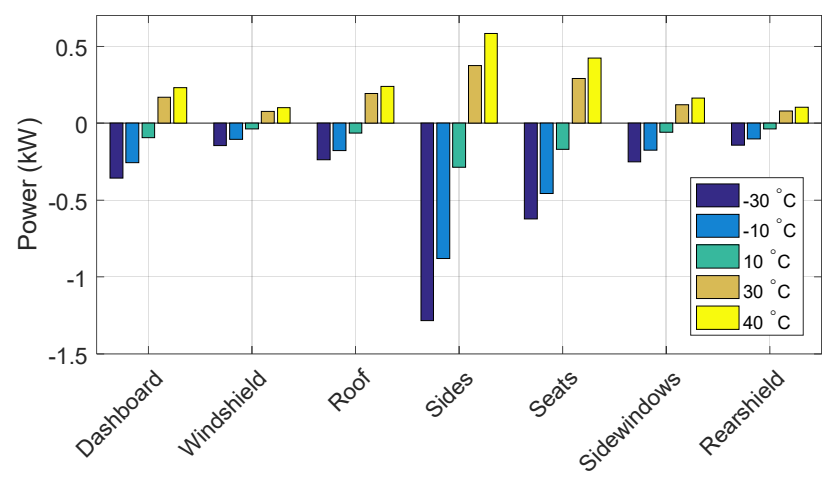

Fig. 6. Simulated cabin heat flows for a midsize electric vehicle [9]. 
Fuel heaters in electric vehicles would also require higher reliability than those in conventional vehicles due to the more frequent usage. In a recent study [84], an integrated heating system was modeled numerically for a cabin and battery to investigate heat transfer in an electric vehicle. The model consisted of a coolant heat exchanger, air heat exchanger, and fuel burner for combustion.

In comparison, heat pumps have been considered as one of the most efficient cabin heating systems in hybrid and electric vehicles [14], [58]. Heat pumps have been commonly used for residential and commercial buildings as heating devices because of their high energy efficiency [85]. Even though heat pump technology is a beneficial choice for heating in EVs, it still has limitations such as low efficiency under cold conditions [13], [86]. Typically, under $-20^{\circ} \mathrm{C}$, heat pumps are less efficient than electric heaters and cannot fulfill the cabin heating power requirement of typical passenger vehicles. Therefore, a system combining a heat pump and a PTC heater has been proposed for electric vehicles [9], [87]. Different methods of range extension in cold conditions for electric vehicles were reviewed by Zhang et al. [88]. They focused on the reduction of climate loads such as ventilation, ambient, and heating loads, and different heat pump systems. It was shown in the research that reducing ventilation loads and using a heat pump system are the most promising solution for increasing the vehicle range.

Jeffers et al., studied zonal heating strategies by experimental evaluations and over a 20 -minute warm-up period their results showed between $5.5 \%$ and $28.5 \%$ reduction for the energy consumption of cabin heating energy [48]. Another study on localized heating and cooling by Chen et al. indicated that HVAC energy consumption could be reduced by $37 \%$ [89]. Thermoelectric (TE) cooling and heating modules were used in this study for controlling the cabin thermal comfort. The local cooling and heating can adapt to the number of passengers easily while zonal control allows more flexibility. However, the system itself can be quite expensive and requires substantial amount of control development.

The reuse of the excess recuperation energy for cabin heating was evaluated to increase overall energy efficiency of electric vehicles [90]. A $6 \mathrm{~kW}$ brake resistor was used which produced up to $12 \%$ reduction in total energy consumption. The highest benefit was obtained at $5-15^{\circ} \mathrm{C}$ because higher heating portion of the cabin could be covered. In another study, an active control strategy was introduced for regenerative braking taking into account the battery thermal response [91]. In plug-in hybrid vehicles, the vehicle system control can have important influence on cabin thermal management and total energy consumption. For instance, fuel saving potential was evaluated by optimizing PHEV system control and using engine waste heat for cabin heating [92].

A recent research summarized studies showing the influence of cabin thermal loads on driving range [88]. There are basically two ways to reduce the power consumption of cabin thermal management in EVs; 1) reduction of cooling and heating loads, and 2) improvement of the thermal system efficiency. Based on the analysis, it seems that the best benefits would be achieved with novel HVAC system structures and advanced controls rather than purely using advanced cabin materials or increasing thermal isolation. Furthermore, one key issue in improving the global efficiency of cabin heating is taking into account the increasing variability in winter weather meaning that the system should be able to adapt to local climate conditions. One solution could be the higher modularity of the HVAC and heating system allowing to choose suitable system configuration and control settings for given weather conditions.

\section{CABIN PRECONDITIONING}

Cabin preconditioning can reduce substantially the energy required to ensure the cabin thermal comfort. In conventional vehicles, cabin preconditioning is usually done by an additional portable electric heater or by fuel-operated heaters. For rechargeable hybrid and electric vehicles, the charging system can provide power for the vehicle cooling and heating system to precondition the vehicle. Many research studies show that the benefit of the cabin preconditioning can be significant especially in cold climate conditions. Based on the simulations of two cycle test in the Environment Protection Agency (EPA) by Barnitt et al., the plug-in hybrid vehicle electric range could be increased by $19 \%$ and electric vehicle range by $4 \%$ by cabin preheating in $-6.7^{\circ} \mathrm{C}$ ambient temperature [93]. Regional and temporal differences on operating range were investigated by Kambly and Bradley and they concluded that the preconditioning in warm conditions could increase the electric vehicle range by almost $10 \%$ [94]. It was also found that the benefits available from cabin preconditioning are strongly dependent on the time of day. An active battery thermal management with cabin preconditioning was found to improve the EV energy efficiency by $9 \%$ in $40{ }^{\circ} \mathrm{C}$ and $8 \%$ in $-10{ }^{\circ} \mathrm{C}$ [95]. The cabin preconditioning was considered better than standby battery thermal management in order to lower the energy consumption during driving. The effects of cabin preconditioning time and ambient temperature on an electric Nissan Leaf were investigated by Nerling et al. [96]. At $-6^{\circ} \mathrm{C}$ ambient temperature, a 20 -minute preconditioning increased the range by $5 \%$ whereas 150 -minute preconditioning could extend the range by $14 \%$.

Cabin preconditioning is also interesting when a vehicle is exposed to the sun that may increase radically the interior temperature. For decrease the cooling load and increase passenger comfort, different methods have been proposed for cooling down the cabin temperature before driving. Al-Zareer et al. proposed a portable system that has one-liter container of liquid compressed air [97]. The system is very simple and the liquid to vapor flashing lasts only five second, and after 55 seconds, all the liquid air is vaporized. According to the research results, the one-liter container with 5.0 bar pressure was able to reduce temperature by $12.0{ }^{\circ} \mathrm{C}$ and $15.2{ }^{\circ} \mathrm{C}$ when the pressure was 9.0 bars. A research study by Pan et al. evaluated the benefits of a solar collector mechanism with supercapacitors and wireless power transfer to cool down the vehicle cabin [98]. The maximum efficiency of the wireless power transfer was little over $60 \%$ and maximum output power only about two watts. Two preconditioning approaches for an electric vehicle cabin were introduced based on a secondary 

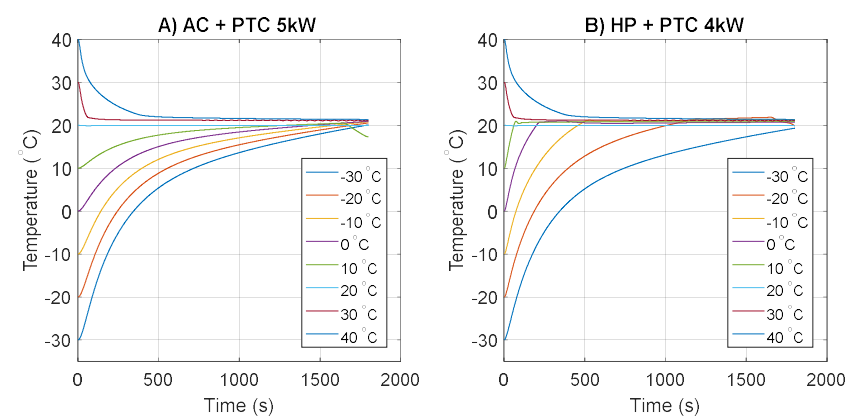

Fig. 7. Simulated cabin preconditioning with different HVAC system configurations [9].

loop water-to-water heat pump system in [99]. The first approach was a user triggered cabin preconditioning and the second approach was using monitored information of the driver movements to trigger correctly the preconditioning.

Fig. 7 illustrates a simulated cabin preconditioning of an electric vehicle cabin with two thermal management systems in different ambient temperatures [9]. The thermal management configurations of the HVAC system are A) A/C and PTC heater of $5 \mathrm{~kW}$, and B) Heat pump and PTC heater of $4 \mathrm{~kW}$. The simulated results show that the heat pump provides much faster cabin preconditioning to $20^{\circ} \mathrm{C}$ temperature.

\section{STATE-OF-THE-ART TECHNOLOGIES FOR CABIN THERMAL MANAGEMENT}

\section{A. Heat Pumps}

Due to the increase of electrified vehicles, more attentions have been directed to the development of automotive heat pumps. Several review studies have been published that describe the air conditioning and heat pump system including operation, configurations and performance characteristics [14], [58], [85]. The current heat pump systems in vehicles are using the vapor compression cycle (VCC) that can provide cabin cooling and heating. Often, a 4-way valve for reversing the refrigerant flow does the change between cooling and heating operation. Other heat pump technologies have been proposed for automotive use such as magnetocaloric heat pumps [100] and thermoelectric heat pumps based on Peltier-effect [101]. The vapor-compression systems in vehicles are reaching their maximum efficiency, which has directed the development towards using more innovative technologies that can further improve the performance of standard systems. This section concentrates on presenting research studies that introduce different technologies or methods for improving current performance of automotive heat pumps.

Heat pump technology is considered as promising heating solution for electric vehicles. Research studies indicate that in mild conditions, ambient temperature higher than $-10{ }^{\circ} \mathrm{C}$, the heating capacity of a heat pump using $\mathrm{R} 134$ a refrigerant is high enough for passenger thermal comfort but in colder conditions an additional heater is required [102], [103]. Fig. 8 presents a heat pump operation for heating and cooling of the cabin. Feng and Hrnjak studied the performance of an air conditioning-heat
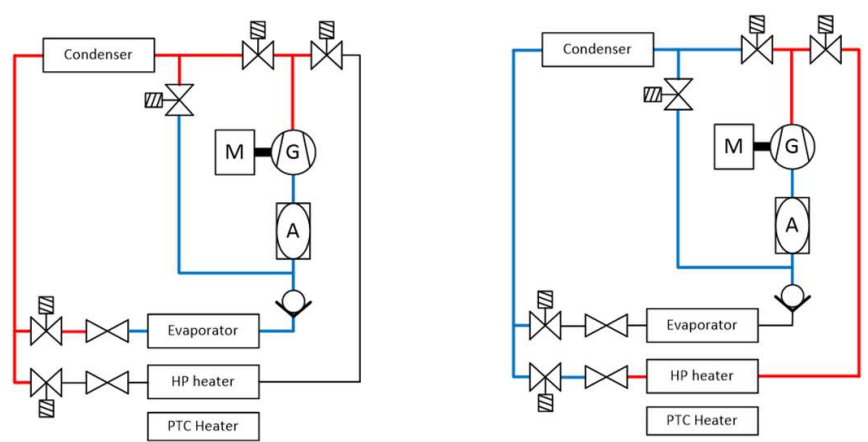

Fig. 8. Heat pump operation: Cooling cycle on the left side and heating on the right side.

pump system based on the platform of Nissan Leaf [13]. They evaluated the effects of indoor and outdoor airflow rates, compressor speed, and expansion valve opening on heating capacity. The experimental results showed that the heating capacity was insufficient at very low ambient conditions but by controlling sub-cooling with the expansion valve could reduce energy consumption by $10 \%$ with $\mathrm{R} 134$ a refrigerant and even more with other type of refrigerants [13]. In addition, they found that the refrigerant charge amount was much larger in $\mathrm{A} / \mathrm{C}$ operation than for heating operation.

The heating performance of heat pumps can be improved by using waste heat from powertrain electrical components. Cho et al. demonstrated this when they evaluated the performance of a coolant-source heat pump in an electric bus [104]. A performance evaluation of a heat pump using R134a refrigerant in connection with a diesel engine was performed in [105]. In the experimental system, the heat pump used ambient air, engine coolant, and engine exhaust gas as heat sources. The results showed that the highest coefficient of performance (COP) was reached with engine coolant as heat source. The feasibility was investigated for a dual-source heat pump that used air and waste heat as heat sources. Performance measurements were carried out at various operating temperatures of the heat pump and in various modes including air source-only, waste heat-only and with both heat sources [106].

Three different methods for cabin heating are presented in Fig. 9 [9]. Many of the first electric vehicle models have only an A/C system with a powerful PTC heater for cabin heating as illustrated in the first option (A) in Fig. 9. The option B is getting more common in many of the modern BEVs and plugin hybrid vehicles. Because of the heat pump, the size of the PTC heater can be significantly reduced. The option $\mathrm{C}$ includes the possibility to harvest waste heat typically from powertrain components. This technology is getting more and more attention as the harvesting methods are getting more efficient and cost effective.

Heat pumps may suffer from a lower performance due to the frosting particularly when ambient temperature is low and humidity high. Therefore, the development of defrosting technologies is considered as a crucial for the application of heat pump systems in electrified vehicles. Zhou et al. carried 

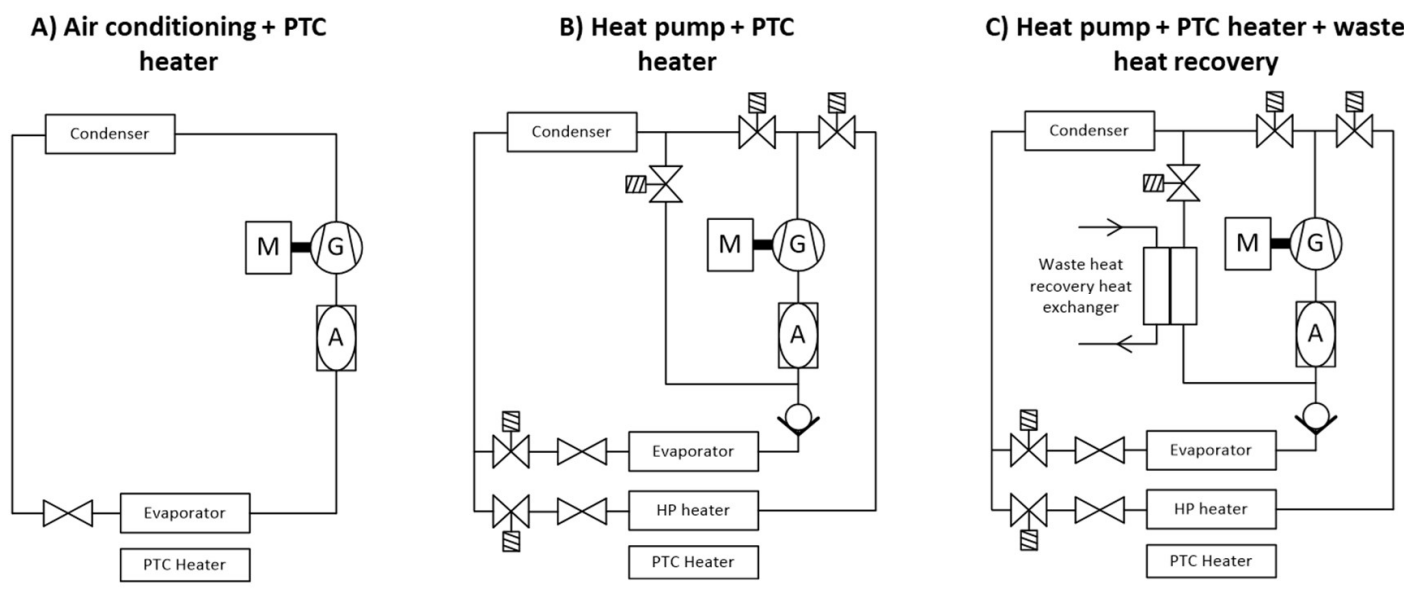

Fig. 9. Different configurations for cabin heating and cooling system.

out a research study with an experimental heat pump system designed for low temperature operation having a defrost technology [107]. They found that the exterior heat exchanger got frost easily in cold and high humidity conditions and proposed a fast defrosting method based on an increased temperature and enhanced gas injection. The experimental results showed that at ambient temperature of $-20{ }^{\circ} \mathrm{C}$ and relative humidity of $80 \%$, for fully defrosting an exterior heat exchanger could be controlled under 100 seconds [107]. Ahn et al. proposed a dehumidifying heat pump that uses a waste heat source for improving the system efficiency but not reducing the heating capacity typical to electric vehicles [108]. Ahn et al. also studied effective dehumidification by a heat pump with a dual-evaporator system in electric vehicles [109]. A research study by Steiner and Rieberer concluded that incorrectly chosen defrost starting time reduced the efficiency of the heat pump system significantly [110].

An anti-fogging air curtain concept with continuous operation for windshields was proposed in [111] in order to maximize the utilization of recirculated air in winter conditions. The study evaluated the performance of an air-source heat pump with different return air ratios by experimental tests at $20{ }^{\circ} \mathrm{C}$. In the ambient temperatures from $-5{ }^{\circ} \mathrm{C}$ to $-20{ }^{\circ} \mathrm{C}$, the research result showed $46-62 \%$ reduction in heating demand in comparison to using fresh air for cabin conditioning. The maximum ratio of return air was found to be $65-79 \%$, which depends on ambient temperature and driving speed [111].

Li et al. evaluated the performance of a heat pump system with an air-cycle and integration to a blower, turbocharger and heat exchanger [112]. Based on the developed thermodynamic models, it was concluded that the heating performance was better when the heat pump was using an installation in which the blower and turbocharger were before the compressor in comparison a configuration where the blower would be before the turbine. The developed air-cycle with the turbocharger was compared to an electric heater system with a PTC in similar operating conditions and about $23 \%$ power savings was observed. It was also concluded that the temperature range for operation could be wider in cold conditions in comparison to the conventional heat pumps using vapor compression cycle [112].
Alternative refrigerants have been proposed and some are already implemented in automotive $\mathrm{A} / \mathrm{C}$ systems and heat pumps, because of to the weak performance of R134a heat pumps at low operating temperatures. Two alternative refrigerants, R744 and R445A, were investigated because of their relatively low Global Warming Potential (GWP) and benefits over R134a in heat pump systems [15]. As these refrigerants are operated at higher system pressures, the heat pump performance is improved at low operating temperatures. The higher refrigerant densities at the compressor inlet is a part of the reason for the better performance. The research concluded that R445A had marginally lower performance in air conditioning operation compared to R134a but it was overall a good option for A/C-HP systems based on its overall performance. The R744 had much higher COP and heating capacity than R134a especially in low ambient temperatures.

Heat pump technology using $\mathrm{CO}_{2}$ as refrigerant is an established technology for building thermal management [113]. The performance characteristics of a $\mathrm{CO}_{2}$ heat pump system in fuel cell vehicles were investigated by Kim et al. [114], [115]. Their research focused on improving the efficiency of a heat pump by recovering heat from the fuel cell stack exhaust with different heat exchanger arrangements. Steiner and Rieberer developed a transient model of a reversible heat pump system with $\mathrm{CO}_{2}$ refrigerant aiming at analyzing the influence of defrosting start time [110].

At very low ambient temperatures, the performance degradation of heat pump systems is practically unavoidable. Different solutions have been proposed among others is injecting vapor refrigerant that has been used as a solution to reduce the degradation in heat pump systems of residential buildings. This technology has also been proposed for electric vehicle applications. Kwon et al. investigated a heat pump system that was using an electric scroll compressor for the vapor injection [86]. Their research demonstrated that the heat pump performance was improved because of the higher workload of the compressor and increased heat recovery at the evaporator. Qin et al. showed that in an air-to-air heat pump using a refrigerant injection the heating capacity is possible to increase more than $30 \%$ and the heat pump could cover heating demand in $-20{ }^{\circ} \mathrm{C}$ with $50 \%$ cabin air recirculation [116]. 
Many studies show significant energy savings by using a heat pump A/C system in electrified vehicles. However, the industry lacks on practical application for overcoming some important obstacles among others efficiency in cold conditions, exterior heat exchanger defrosting, component and overall system optimization. Some solutions have been presented in the literature for these obstacles but more experimental research and development work is needed especially for the robust and efficient operation of cooling and heating. For instance, exploiting waste heat is beneficial for heating mode but not necessarily for cabin cooling.

\section{B. Thermal Energy Buffering and Heat Exchangers}

Different types of sensible or latent thermal energy storages could provide solutions for efficient thermal management of cabin. A simulation of a TES (thermal energy storage) for improving the performance of cabin heating in electric vehicles was recently presented [117]. The results suggested thermal energy storage could reduce the energy consumption by $25 \%$. A thermal battery concept by exploiting advanced metal hydrides was introduced for vehicle cabin cooling and heating. The idea of having higher energy density was based on the differences occurring in hydrogen equilibrium pressures [118]. The working hydrides have matching thermodynamic properties, consisting of $\mathrm{MgH} 2$ (high temperature hydride) and TiMnV (low temperature hydride). The developed concept thermal battery was successfully tested in a laboratory. In addition, the capability of storing heat in an evaporator as a part of the air conditioning was analyzed by Zhang and Canova [119]. Fuel economy increased by $2 \%$ with dynamic programming optimization and by using PCM as an energy buffer in the evaporator, the energy storage capability was significantly increased. However, increased cost and weight are typically not justified for thermal energy storage with the current limited benefits of increasing heating efficiency.

Because of the lack of excess heat in electrified vehicles, thermal storages could be used for providing an effective storage density and thermally high discharging power for heating. A novel concept for thermal energy storage was introduced by Dreißigacker and Belik [120]. The storage has high operating temperature that is generated by direct resistant heating. The heat is directed into the cabin via a bypass operation. The main design factors of the system influencing on efficiency and system flexibility were found to be the geometric design, material properties, and thermal insulation. The research results indicated that alternative thermal technologies such as PCM or thermochemical systems would provide elevated storage densities but require more complicated heat transfer systems, which in turn would decrease the effective storage density and operational flexibilities.

Heat exchangers (HEX) are among the most important components in the vehicle thermal management [121]. In HEX, the heat transfer coefficient and temperature distribution can be non-uniform depending on the configuration of fins of a heat exchanger [122]. In vehicle thermal management, heat exchangers are typically used for transferring heat between a fluid and surrounding air (e.g. radiator), and between two fluid circuit systems such as in secondary loop heat pumps [121]. Depending on the design, a typical heater core can also work as heating and cooling heat exchanger [123]. Advanced thermal system development requires accurate simulation model that could be challenging to develop especially because the thermal transfer can be different depending on the operating conditions [123]. However, detail component thermal models enables further development even the basic thermal components and create optimal designs [124].

\section{Thermal System Control}

For PHEVs, the engine temperature tend to fluctuate due to the engine shuts down and the loads vary. When there is not enough waste heat provided by the engine, the heat will be provided by the battery system, motors, generators, and power electronics. Conventionally, the vehicle thermal management concentrates on the heat production of the combustion engine. In PHEVs, the energy and thermal management is a trade-off [125]. It is typically a multi-variable optimization problem, in which several variables are taken into account such as battery state-of-charge and engine internal temperature [126]. Based on simulation results, cabin thermal loads can have a significant influence on the energy management system (EMS) [127]. In general, the prediction of vehicle power demand in variable temperatures is challenging with high non-linearity [125]. Cabin heating and cooling are taken into account when considering the energy management strategy of PHEVs [19], [84], [128]. For example, Shin et al. developed an integrated powertrain energy and thermal management simulation model in MATLAB/Simulink for a PHEV [19]. The simulation results showed a fuel economy increase of $9.5 \%$ in comparison to a conventional EMS. Gissing et al. developed a predictive energy and thermal management model for a hybrid vehicle with a range-extender [128]. The objective was to increase the use of the engine waste heat without influencing on the acoustic comfort characteristics. The simulations with a verified model demonstrated a $12 \%$ saving in operation costs compared to the reference control strategy. Vehicle electric auxiliary devices such as water pumps and compressors facilitate the development of advanced control system [129].

The combustion engine excess heat can be used for heating the battery and cabin in plug-in hybrid vehicles. However, the excess heat may not be available for heating purposes in cold conditions because the engine temperature has to be considered for energy efficient operation and exhaust emission control [127]. In general, plug-in hybrid vehicles should have a dedicated thermal management system that incorporates the engine and battery operation as well as cabin heating and cooling. A multi-domain simulation model of a HEV that includes power flow of the powertrain and cabin heat flow was presented in [130]. The investigation revealed that with a simple energy management strategy, the over-consumption was $19 \%$ because of the heating system. In comparison, with more advanced control strategy, the over-consumption was reduced to $12 \%$ [130].

An energy efficient passenger comfort control based on a Markov Decision Process was recently developed by Brusey et 
al. [35]. They showed that Reinforcement Learning could reliably produce a controller that deliver better passenger control while using less energy in comparison to existing handcoded control approaches. On the other hand, thermoelectric devices still suffer from low efficiency therefore more research needs to be done to make them beneficial in vehicles [131].

Model predictive control (MPC) based optimization has been implemented into cabin thermal management of hybrid and electric vehicles for improved energy efficiency. Amini et al. demonstrated up to $5.3 \%$ fuel savings for cabin and battery cooling by using hierarchical two-layer MPC control [132]. Wang et al. presented that by using nonlinear model predictive control (NMPC) to minimize the energy consumption of the $\mathrm{A} / \mathrm{C}$ system and regulate the cabin temperature for hybrid and electric passenger cars, up to $9 \%$ of energy efficiency improvement can be resulted in the energy efficiency of the $\mathrm{A} / \mathrm{C}$ system [133]. Esen et al. discussed the advantages of using MPC for hybrid vehicles cabin heating, where up to $3 \%$ fuel savings can be achieved compared to a reference baseline controller [134].

\section{Other Technologies}

Rather than the centralized HVAC cabin thermal management, that is typically implemented, zoned heating and cooling provide passenger tailored thermal conditioning and better energy efficiency. Heated seats are popular in most of the passenger cars while cooled seats, or "seat conditioning", methods have been introduced to maintain passenger conform while reducing cooling energy [135], [136]. Chest, lap, face, and other localized cooling are also effective methods to achieve targeted local cooling [137]. Thermoelectric (TE) devices for localized cooling have been studied and predicted to achieve $29 \%$ compressor power saving while meeting equivalent comfort compared to traditional HVAC system [138]. Due to the need of reducing thermal energy consumption in electric vehicles, approaches that are more complete have been introduced [20], [139]. Steiner and Mladek introduced an occupant centered holistic approach for reducing energy consumption including technologies of energy harvesting with photovoltaic cells and shock absorbers, and preconditioned battery as heat source [110]. Because electrified vehicles do not have a lot of excessive heat for the cabin heating, zonal and local heating solutions can be considered well suitable for increasing the heating energy efficiency.

Passive thermal management technologies are typically used for powertrain components that generate heat and are sensitive to high temperature environment such as battery pack, engine, motors, and power electronics [140]. Recently, there are also trends to integrate passive thermal management systems between powertrain and cabin thermal management components. Zou et al. presented an integrated thermal management system with heat pipe heat exchanger for electric vehicle battery cooling as well as heat pump air conditioning system pre-heating [141]. The results showed that the system met the basic cabin cooling demand under different working conditions, while it can supply about $20 \%$ additional cooling capacity without input power increase.
A passive thermal energy storage system was modeled and simulated for rechargeable electric vehicles by Shahidinejad et al. [142]. The system uses PCM for maintaining a set point of temperature in the vehicle cabin. The PCM system is charged by absorbing heat generated with an electric heater, which is connected to the electric grid. According to the simulation results, the cabin temperature was held on $15^{\circ} \mathrm{C}$ and $21 \%$ increase in the electric range was observed. Similar study was presented in [143] where the development of a heat exchanger with PCM was introduced. The design tests indicated that the electric range could be extended by $20 \%$ in winter conditions. The heat exchanger design mass was $33 \mathrm{~kg}$ and volume of 31 liters.

Photovoltaic system was used in the roof of an electric car to provide ventilation for cabin thermal management [144]. The research objective was to evaluate the ventilation benefit during car parking. The ventilation was done by fans that remove the hot air from the cabin. The measurement results showed that the cabin temperature could be lowered close to the ambient temperature when using the ventilation.

\section{DISCUSSION AND CONCLUSIONS}

A broad review and analysis about cabin thermal management for electrified passenger vehicles is presented in this paper. The review takes into account various vehicle technologies and thermal management systems as thermal management has a vital role for ensuring the safe and robust operation of electrical components as well as passenger comfort. In addition, various vehicle cabin thermal modeling techniques and cabin thermal comfort have been discussed, with emphases on the new challenges for electrified vehicles. Last but not the least, the state-of-the-art thermal system control technologies have been reviewed and presented.

For electrified vehicles, an efficient thermal management is essential for battery protection and performance as well as thermal comfort and adequate driving range. Energy consumption can drastically increase in hot and cold ambient conditions. Because of the lack of natural heat sources, electrical components and cabin heating require considerable amount of energy that is taken from the battery. Thermal management of electrified vehicles have been recently improved by introducing heat pump systems, which can significantly increase the heating efficiency especially in mild temperature conditions. However, more research and development work is required for ensuring the practical robustness and efficiency of the combination heat pump and $\mathrm{A} / \mathrm{C}$ systems. Thermal energy storages have been studied but often the increased cost and weight cannot be justified with the limited benefits of increasing heating efficiency.

Because most of the vehicles operate in the areas where the climate is more likely to be warm than cold, air conditioning is often being used and can be considered as the most important thermal load for passenger vehicles. Automotive air conditioning systems can be considered as mature technology but there is increasing amount of research focusing on the alternative refrigerants. Currently used refrigerants have high global warming potential; hence, restrictions have already been 
put in place for automotive refrigerants in the European Union. The alternative refrigerants may need new system designs and have different performance characteristics. Especially $\mathrm{CO}_{2}$ as refrigerant (R744) has drawn a lot of interest because of the low global warming potential and non-toxicity. However, an air conditioning (or heat pump) system using R744 would be entirely new system in comparison to conventional systems due to the much higher operating pressure and different operating characteristics.

Traditionally, many cabin thermal management solutions are designed for consumer benefit, and therefore, energy efficiency may not have been the primary focus area in relation to consumer experience. Through electrification, passenger cars have become more energy efficient and the importance of thermal management have increased especially for reducing energy losses. New technologies have been introduced and proposed (e.g. heat pumps and thermal storages) due to the lack of excess available heat or need to conserve energy especially in battery electric vehicles. Electric heaters are a powerful solution for the cabin heating but alternatives have been developed to reduce the cabin thermal losses. In cold regions, cabin preheating is common practice being efficient solution for electric and hybrid vehicles.

As the number of electrified vehicles is increasing, the cabin thermal management and HVAC technology are becoming more important in the future. However, only the mature technologies are typically implemented in production vehicles. For instance, among zonal heating and cooling technologies many mature technologies are already being implemented in vehicles. An apparent future trend is the development of advanced system controls with the aid of modern simulation tools. This approach facilitates the adoption of active management technologies but may increase the software development costs.

Reducing the heat load of the cabin have been often recognized as a key factor for improving the thermal management efficiency and lowering the HVAC load. Considering that hotter weather conditions are more frequent, cabin thermal soak is going be to an important factor for cooling demand. Due to the large window area of present day vehicles, more focus should be given for the development of adaptive materials such as photovoltachromic devices.

It is reasonable to envision that adaptability of the vehicle thermal system may not be easily implemented, at least not cost effectively. Therefore, the local climate could be taken into account by optimizing the thermal system efficiency based on whether if it is mostly cold or hot weather. In conventional vehicles, the engine block heater has only been used in cold regions. Furthermore, the system adaptability is definitely topic that needs more research focus in the future.

\section{ACKNOWLEDGMENT}

The authors would like to acknowledge the financial support from the Jenny and Antti Wihuri Foundation. The authors also wishes to thank University of Helsinki and McMaster University for technical support.

\section{REFERENCES}

[1] M. Weiss, M. K. Patel, M. Junginger, A. Perujo, P. Bonnel and G. van Grootveld, "On the electrification of road transport - Learning rates and price forecasts for hybrid-electric and battery-electric vehicles," Energy Policy, vol. 48, no. 1, pp. 374-393, 2012.

[2] B. Bilgin, P. Magne, P. Malysz, Y. Yang, V. Pantelic, M. Preindl, A. Korobkine, W. Jiang, M. Lawford and A. Emadi, "Making the Case for Electrified Transportation," IEEE Transactions on Transportation Electrification, vol. 1, no. 1, pp. 4-17, 2015.

[3] M. A. Tamor, C. Gearhart and C. Soto, "A statistical approach to estimating acceptance of electric vehicles and electrification of personal transportation," Transportation Research Part C: Emerging Technologies, vol. 26, no. 1, pp. Emerging Technologies. 26(1):125-134, 2013.

[4] Moreno, G., Narumanchi, S., Bennion, K., et al., "Gaining traction: thermal management and reliability of automotive electric traction-drive systems," IEEE Electrification Magazine, vol. 2, no. 2, pp. 42-49, 2014.

[5] M. Dijk, P. Wells and R. Kemp, "Will the momentum of the electric car last? Testing an hypothesis on disruptive innovation," Technological Forecasting and Social Change, vol. 105, no. 1, pp. 77-88, 2016.

[6] G. Shu, J. Zhao, H. Tian, H. Wei, X. Liang, G. Yu and L. Liu, "Theoretical Analysis of Engine Waste Heat Recovery by the Combined ThermoGenerator and Organic Rankine Cycle System," SAE Technical Paper 2012-01-0636, pp. 1-9, 2012.

[7] N. R. Jankowski and F. P. McCluskey, "A review of phase change materials for vehicle component thermal buffering," Applied Energy, vol. 113 , no. 1, pp. 1525-1561, 2014.

[8] C. Huber, A. Jossen and R. Kuhn, "Novel Latent Heat Storage Devices for Thermal Management of Electric Vehicle Battery Systems," in Sustainable Automotive Technologies, Heidelber, Springer, 2013, p. 295.

[9] A. Lajunen, "Energy Efficiency and Performance of Cabin Thermal Management in Electric Vehicles," SAE technical paper 2017-01-0192, p. 9, 2017.

[10] Y. H. Shin, S. Sim and S. C. Kim, "Performance Characteristics of a Modularized and Integrated PTC Heating System for an Electric Vehicle," Energies, vol. 9, no. 1, pp. 1-11, 2016.

[11] X. Jin, J.-q. Li, C.-n. Zhang and P.-e. Wu, "Researches on Modeling and Experiment of Li-ion Battery PTC Self-heating in Electric Vehicles," Energy Procedia, vol. 104, no. 1, pp. 62-67, 2016.

[12] R. Musat and E. Helerea, "Characteristics of the PTC Heater Used in Automotive HVAC Systems," in Emerging Trends in Technological Innovation of the series IFIP Advances in Information and Communication Technology, Costa de Caparica, Portugal, Springer, 2010, pp. 461-468.

[13] L. Feng and P. Hrnjak, "Experimental Study of an Air Conditioning-Heat Pump System for Electric Vehicles," SAE Technical Paper 2016-01-0257, pp. 1-7, 2016.

[14] Z. Qi, "Advances on air conditioning and heat pump system in electric vehicles - A review," Renewable and Sustainable Energy Reviews, vol. 38, pp. 754-764, 2013.

[15] A. Musser and P. S. Hrnjak, "Mobile Heat Pump Exploration Using R445A and R744," in International Refrigeration and Air Conditioning Conference, Purdue, 2014, pp. 1-10.

[16] A. Lajunen, Y. Yang and A. Emadi, "Recent Developments in Thermal Management of Electrified Powertrains," IEEE Transactions on Vehicular Technology, vol. 67, no. 12, pp. 11486-11499, 2018.

[17] S. Shojaei, A. McGordon, S. Robinson, J. Marco and P. Jennings, "Developing a model for analysis of the cooling loads of a hybrid electric vehicle by using co-simulations of verified submodels," Proc IMechE Part D: J Automobile Engineering, vol. 1, no. 1, p. 1-19, 2017.

[18] L. Broglia, G. Autefage and M. Ponchant, "Impact of passenger thermal comfort and electric devices temperature on range: a system simulation approach," in Electric Vehicle Symposium (EVS), Los Angeles, USA, 2012, pp. 1-8.

[19] H. Shin, S. Park, H. Kim and I. Yang, "Development of an integrated energy management strategy with cabin heating for plug-in hybrid electric vehicle," in Tenth International Conference on Ecological Vehicles and Renewable Energies (EVER), Monte Carlo, Monaco, 2015, pp. 1-10.

[20] C. Bouvy, S. Baltzer, P. Jeck, J. Gissing, T. Lichius and L. Eckstein, "Holistic Vehicle Simulation using Modelica - An Application on Thermal Management and Operation Strategy for Electrified Vehicles," in Proceedings of the 9th International Modelica Conference, Münich, Germany, 2012, pp. 263-270. 
[21] T. Kiss, J. Lustbader and D. Leighton, "Modeling of an Electric Vehicle Thermal Management System in MATLAB/Simulink," SAE Technical Paper 2015-01-1708, pp. 1-11, 10.4271/2015-01-1708.

[22] J. Pokorny, J. Fiser and M. Jicha, "Virtual Testing Stand for evaluation of car cabin indoor environment," Advances in Engineering Software, vol. 76, no. 1 , pp. $48-55,2014$

[23] T. Ye, "A Multidisciplinary Numerical Modeling Tool Integrating CFD and Thermal System Simulation for Automotive HVAC System Design," SAE Technical Paper 2012-01-0644, pp. 1-12, 2012.

[24] D. Ghosh, M. Wang, E. Wolfe, K.-h. Chen, S. Kaushik and T. Han, "Energy Efficient HVAC System with Spot Cooling in an Automobile Design and CFD Analysis," SAE Int. J. Passeng. Cars - Mech. Syst., vol 5, no. 2, pp. 885-903, 2012.

[25] Z. Wang, J. Han, A. Alajbegovic, T. Kuthada, D. Stoll, C. Makens and T. Schwenn, "Long term transient cabin heating simulation with multiple fluid node approach," in Vehicle Thermal Management Systems Conference Proceedings (VTMS11), Coventry, UK, 2013, pp. 319-333.

[26] M. A. Fayazbakhsh and M. Bahrami, "Comprehensive Modeling of Vehicle Air Conditioning Loads Using Heat Balance Method," SAE Technical Paper 2013-01-1507, pp. 1-14, 2013.

[27] B. Torregrosa-Jaime, F. Bjurling, J. M. Corberán, F. Di Sciullo and J. Payá, "Transient thermal model of a vehicle's cabin validated under variable ambient conditions," Applied Thermal Engineering, vol. 75, no. 1, pp. 45-53, 2015.

[28] H. Lee, Y. Hwang, I. Song and K. Jang, "Transient thermal model of passenger car's cabin and implementation to saturation cycle with alternative working fluids," Energy, vol. 90, no. 2, pp. 1859-1868, 2015.

[29] Y. Ozeki, H. Nagano, T. Kataoka, H. Iwase, H. Doi, R. Mizushima, I. Kohri and S. Kato, "Ventilation Characteristics of Modeled Compact Car Part 5 - Scaled Model Experiment for Heat Transfer Characteristics," SAE Technical Paper, pp. 1-7, 2012.

[30] H. Nagano, M. Inoue, Y. Ozeki, W. Zhang, Y. Kitano, K. Matsunaga, S. Kato and I. Kohri, "Ventilation Characteristics of Modeled Compact Car Part 6 - Numerical Analysis of Heat Transfer Characteristics by CRI," SAE Technical Paper 2012-01-0640, pp. 1-7, 2012.

[31] F. Nielsen, S. Gullman, F. Wallin, A. Uddheim and J.-O. Dalenbäck, "Simulation of Energy Used for Vehicle Interior Climate," SAE Int. J. Passeng. Cars - Mech. Syst., vol. 8, no. 4, pp. 1218-1234, 2015.

[32] C. Walgama, S. Fackrell, M. Karimi, A. Fartaj and G. W. Rankin, "Passenger Thermal Comfort in Vehicles - A Review," Proc IMechE Part D: J Automobile Engineering, vol. 220, no. 5, pp. 543-562, 2006.

[33] S. H. Toon, H. S. Ahn and Y. H. Choi, "Numerical study to evaluate the characteristics Of HVAC-related Parameters to reduce $\mathrm{CO} 2$ concentrations in cars," International Journal of Automotive Technology vol. 17, no. 6, p. 959-966, 2016.

[34] K. Imai, T. Kataoka, T. MASUDA and T. Inada, "New Evaluation Method of Transient and Non-Uniform Environment in a Passenger Compartment," SAE Int. J. Passeng. Cars - Mech. Syst., vol. 5, no. 2, pp. 876-884, 2012.

[35] J. Brusey, D. Hintea, E. Gaura and N. Beloe, "Reinforcement learningbased thermal comfort control for vehicle cabins," Mechatronics, vol. 50, no. 1, pp. 413-421, 2017.

[36] P. Danca, A. Vartires and A. Dogeanu, "An Overview of Current Methods for Thermal Comfort Assessment in Vehicle Cabin," Energy Procedia, vol. 85, no. 1, pp. 162-169, 2016.

[37] K. R. Kambly and T. H. Bradley, "Estimating the HVAC energy consumption of plug-in electric vehicles," Journal of Power Sources, vol. 259, pp. 117-124, 2014.

[38] M. Ivanescu, C. Neacsu, S. Tabacu and I. Tabacu, "The Human Thermal Comfort Evaluation inside the Passenger Compartment," in World Automotive Congress, Budapest, Hungary, 2010, pp. 1-13.

[39] H. Zhang, Human thermal sensation and comfort in transient and nonuniform thermal environments, Berkeley, California: Doctoral Dissertation, College of Environmental Design, University of California, Berkeley, 2003.

[40] M. Simion, L. Socaciu and P. Unguresan, "Factors which Influence the Thermal Comfort Inside of Vehicles," Energy Procedia, vol. 85, no. 1, pp. 472-480, 2016.

[41] P. O. Fanger, "Proposed Nordic standard for ventilation and thermal comfort," in International Conference On Building Energy Management, 1980, pp. 609-614.

[42] A. Alahmer, A. Mayyas, A. A. Mayyas, M. A. Omar and D. Shan, "Vehicular thermal comfort models; a comprehensive review," Applied Thermal Engineering, vol. 31, no. 6-7, pp. 995-1002, 2011.
[43] ISO 14505-3:2006, Ergonomics of the thermal environment - Evaluation of thermal environments in vehicles Part 3: Evaluation of thermal comfort using human subjects, ISO, 2006

[44] ANSI/ASHRAE Standard 55-2013, Thermal environmental conditions for human occupancy, Atlanta, GA: American Society of Heating, Refrigerating and Air-Conditioning Engineers, 2013.

[45] K. Blazejczyk, Y. Epstein, G. Jendritzky, H. Staiger and B. Tinz, "Comparison of UTCI to selected thermal indices," International Journal of Biometeorology, vol. 56, no. 3, p. 515-535, 2012.

[46] D. Fiala, Dynamic Simulation of Human Heat Transfer and Thermal Comfort, Doctoral Dissertation, Institute of Energy and Sustainable Development, De Montfort University, Leicester, UK, 1998.

[47] M. Fojtlín, J. Fišer, J. Pokorný, A. Povalac, T. Urbanec and M. Jícha, "An innovative HVAC control system: Implementation and testing in a vehicular cabin," Journal of Thermal Biology, vol. 70, no. Part A, pp. 64$68,2017$.

[48] M. Jeffers, L. Chaney and J. Rugh, "Climate Control Load Reduction Strategies for Electric Drive Vehicles in Cold Weather," SAE International Journal of Passenger Cars - Mechanical Systems, vol. 9, no. 1, pp. 75-82, 2016

[49] G. Karimi, E. C. Chan, J. R. Culham, I. Linjacki and L. Brennan, "Thermal Comfort Analysis of an Automobile Driver with Heated and Ventilated Seat," SAE Technical Paper 2002-01-0222, pp. 1-11, 2002.

[50] K.-h. Chen, S. Kaushik, T. Han, D. Ghosh and M. Wang, "Thermal Comfort Prediction and Validation in a Realistic Vehicle Thermal Environment," SAE Technical Paper 2012-01-0645, pp. 1-14, 2012.

[51] A. Alahmer, M. Abdelhamid and M. Omar, "Design for thermal sensation and comfort states in vehicles cabins," Applied Thermal Engineering, vol. 36, no. 1, p. 126-140, 2012.

[52] C. C. Goh, L. M. Kamarudin, S. Shukri, N. S. Abdullah and A. Zakaria, "Monitoring of carbon dioxide (CO2) accumulation in vehicle cabin," in 3rd International Conference on Electronic Design (ICED), Phuket, Thailand, 2016, pp. 427-432.

[53] W. Ferraris, "Technology evaluation report for auxiliaries for e-A/C, ecompressor and e-heating," 2013, p. 30.

[54] J. C. Menken, J. E. Koerner, T. A. Weustenfeld, K. Strasser and J. Koehler, "Simulative Comparison of Conventional and Secondary Loop Automotive Refrigeration Systems," in Vehicle Thermal Management Systems Conference and Exhibition, VTMS 12, Nottingham, UK, 2015, pp. 511-523.

[55] T. A. Weustenfeld, W. Bauer-Kugelmann, J. C. Menken, K. Strasser and J. Koehler, "Heat flow rate based thermal management for electric vehicles using a secondary loop heating and cooling system," in Vehicle Thermal Management Systems Conference and Exhibition, VTMS 12, Nottingham, UK, 2015, pp. 315-329.

[56] H. S. Hamut, I. Dincer and G. F. Naterer, "Performance assessment of thermal management systems for electric and hybrid electric vehicles," International Journal of Energy Research, vol. 37, pp. 1-12, 2013.

[57] C. Isetti, E. Nannei, S. Lazzari, B. Cerrai and S. Nari, "New climatecontrol units for more energy-efficient electric vehicles: System architecture," in Twelfth International Conference on Ecological Vehicles and Renewable Energies (EVER), Monaco, France, 2017, pp. 1-7.

[58] Q. Peng and Q. Du, "Progress in Heat Pump Air Conditioning Systems for Electric Vehicles - A Review," Energies, vol. 9, no. 4, pp. 1-17, 2016.

[59] K. Harby, "Hydrocarbons and their mixtures as alternatives to environmental unfriendly halogenated refrigerants: An updated overview," Renewable and Sustainable Energy Reviews, vol. 73, no. 1, pp. 1247-1264, 2017.

[60] S. Daviran, A. Kasaeian, S. Golzari, O. Mahian, S. Nasirivatan and S. Wongwises, "A comparative study on the performance of HFO-1234yf and HFC-134a as an alternative in automotive air conditioning systems," Applied Thermal Engineering, vol. 110, no. 1, pp. 1091-1100, 2017.

[61] J. Li, J. Jia, L. Huang and S. Wang, "Experimental and numerical study of an integrated fin and micro-channel gas cooler for a $\mathrm{CO} 2$ automotive air-conditioning," Applied Thermal Engineering, vol. 116, no. 1, pp. 636$647,2017$.

[62] Directive 2006/40/EC of the European Parliament and of the Council of 17 May 2006 relating to emissions from air-conditioning systems in motor vehicles and amending Council Directive 70/156/EEC, Strasbourg: European Parliament, 2006.

[63] M. Jeffers, L. Chaney and J. Rugh, "Climate Control Load Reduction Strategies for Electric Drive Vehicles in Warm Weather," SAE Technical Paper 2015-01-0355, pp. 1-11, 2015. 
[64] H. Khayyam, A. Z. Kouzani and E. J. Hu, "Reducing energy consumption of vehicle air conditioning system by an energy management system," in IEEE Intelligent Vehicles Symposium, Xi'an, China, 2009, pp. 752-757.

[65] H. Khayyam, A. Z. Kouzani, E. J. Hu and S. Nahavandi, "Coordinated energy management of vehicle air conditioning system," Applied Thermal Engineering,, vol. 31, no. 5, pp. 750-764, 2011.

[66] H. Khayyam, "Adaptive intelligent control of vehicle air conditioning system," Applied Thermal Engineering, vol. 51, no. 1-2, pp. 1154-1161, 2013.

[67] N. Javani, I. Dincer and G. F. Naterer, "Thermodynamic analysis of waste heat recovery for cooling systems in hybrid and electric vehicles," Energy, vol. 46, no. 1, pp. 109-116, 2012

[68] S. Papasavva and W. Moomaw, "Comparison between HFC-134a and Alternative Refrigerants in Mobile Air Conditioners using the GREENMAC-LCCP C Model," in 15th International Refrigeration and Air Conditioning Conference at Purdue, West Lafayette, IN, USA, 2014, pp $1-11$.

[69] M.-Y. Lee and D.-Y. Lee, "Review on Conventional Air Conditioning. Alternative Refrigerants. and CO2 Heat Pumps for Vehicles," Advances in Mechanical Engineering, vol. 1, no. 1, pp. 1-15, 2013.

[70] D. W. Lee, "Experimental study on performance characteristics of cold storage heat exchanger for ISG vehicle," International Journal of Automotive Technology, vol. 18, no. 1, p. 41-48, 2017.

[71] D. Marcos, F. J. Pino, C. Bordons and J. J. Guerra, "The development and validation of a thermal model for the cabin of a vehicle," Applied Thermal Engineering, vol. 66, no. 1-2, pp. 646-656, 2014.

[72] C.-Y. Tseng, Y.-A. Yan and J. C. Leong, "Thermal Accumulation in a General Car Cabin Model," Journal of Fluid Flow, Heat and Mass Transfer, vol. 1, no. 1, pp. 48-56, 2014

[73] R. Farrington and J. Rugh, "Impact of Vehicle Air-conditioning on Fuel Economy, Tailpipe Emissions, and Electric Vehicle Range," in Earth Technologies Forum, Washington, D.C., 2000, pp. 1-10.

[74] T. Srisilpsophon, J. Tiansuwan and T. Kiatsiriroat, "Effect of anti-solar glass film on heat transfer and mean radiant temperature inside cabin of air-conditioned vehicle," International Journal of Ambient Energy, vol. 28 , no. 1 , pp. 39-50, 2007.

[75] J. Rugh, L. Chaney, L. Ramroth, T. Venson and M. Rose, "Impact of Solar Control PVB Glass on Vehicle Interior Temperatures, Air-Conditioning Capacity, Fuel Consumption, and Vehicle Range," SAE Technical Paper 2013-01-0553, pp. 1-11, 2013.

[76] L. Horrein, A. Bouscayrol, W. Lhomme and C. Departure, "Impact of heating system on the range of an electric vehicle," IEEE Transactions on Vehicular Technology, vol. 66, no. 6, pp. 4668-4677, 2016.

[77] NHTSA Standard No. 103, Windshield defrosting and defogging systems, Federal Motor Vehicle Safety Standards, DOT \& 571.103, The U.S. Department of Transportation's National Highway Traffic Safety Administration, 2011

[78] Commission Regulation (EU) No 672/2010 of 27 July 2010 concerning type-approval requirements for windscreen defrosting and demisting systems of certain motor vehicles, Brussels, European Commission, 2010.

[79] I. Morris, D. Riordan, J. Walsh and A. Maher, "Evaluation of requirements for the development of a bench test system to test PTC heater in-situ automotive HVAC case units," in IEEE 27th Irish Signals and Systems Conference (ISSC), Londonderry, United Kingdom, 2016, pp. 1-6.

[80] T. Zhang, C. Gao, Q. Gao, G. Wang, M. Liu, Y. Guo, C. Xiao and Y. Y. Yan, "Status and development of electric vehicle integrated therma management from BTM to HVAC," Applied Thermal Engineering, vol 88 , no. 1 , pp. $398-409,2015$.

[81] M. Schmitt and M. Nasri, "Thermal management concept for next generation vehicles," in Tenth International Conference on Ecological Vehicles and Renewable Energies (EVER), Monte-Carlo, Monaco, 2015.

[82] C. Cho, G. Kim, Y. Pyo and W. Lee, "The development of an energyefficient heating system for electric vehicles," in IEEE Transportation Electrification Conference and Expo (ITEC Asia-Pacific), Busan, Korea (South), 2016, pp. 883-885.

[83] M. Humburg, T. Krähling, W. Pfister and A. Wetzel, Commercial Vehicle Fuel Heater with Biodiesel, vol. 110, ATZ, 2008, pp. 36-39.

[84] J.-H. Seo, M. S. Patil, C.-P. Cho and M.-Y. Lee, "Heat transfer characteristics of the integrated heating system for cabin and battery of an electric vehicle under cold weather conditions," International Journal of Heat and Mass Transfer, vol. 117, no. 1, pp. 80-94, 2018

[85] K. J. Chua, S. K. Chou and W. M. Yang, "Advances in heat pump systems: A review," Applied Energy, vol. 87, no. 12, pp. 3611-3624, 2010.
[86] C. Kwon, M. S. Kim, Y. Choi and M. S. Kim, "Performance evaluation of a vapor injection heat pump system for electric vehicles," International Journal of Refrigeration, vol. 74, no. 1, pp. 138-150, 2017.

[87] K. Y. Kim, S. C. Kim and M. S. Kim, "Experimental studies on the heating performance of the PTC heater and heat pump combined system in fuel cells and electric vehicles," International Journal of Automotive Technology, vol. 13, no. 6, p. 971-977, 2012.

[88] Z. Zhang, D. Wang, C. Zhang and J. Chen, "Electric vehicle range extension strategies based on improved AC system in cold climate - a Review," International Journal of Refrigeration, vol. 88, no. 1, pp. 141$150,2018$.

[89] K.-H. Chen, J. Bozeman, M. Wang, D. Ghosh, E. Wolfe and S. Chowdhury, "Energy Efficiency Impact of Localized Cooling/Heating for Electric Vehicle," SAE Technical Paper 2015-01-0352, pp. 1-9, 2015.

[90] J. Lieb, E. Sawazki, M. Brüll and B. Bäker, "Potential of an electric brake resistor to increase the efficiency of electric vehicles," in World Electric Vehicle Symposium and Exhibition (EVS27), Barcelona, Spain, 2013, pp. $1-10$

[91] J. Huang, D. Qin and Z. Peng, "Effect of energy-regenerative braking on electric vehicle battery thermal management and control method based on simulation investigation," Energy Conversion and Management, vol. 105, no. 1 , pp. 1157-1165, 2015.

[92] J. Gissing, P. Themann, S. Baltzer, T. Lichius and L. Eckstein, "Optimal Control of Series Plug-In Hybrid Electric Vehicles Considering the Cabin Heat Demand," IEEE Transactions on Control Systems Technology, vol. 24, no. 3, pp. 1126-1133, 2016.

[93] R. A. Barnitt, A. D. Brooker, L. Ramroth, J. Rugh and K. A. Smith, "Analysis of Off-Board Powered Thermal Preconditioning in Electric Drive Vehicles," in 25th World Battery, Hybrid and Fuel Cell Electric Vehicle Symposium \& Exhibition, Shenzhen, China, 2010, pp. 1-7.

[94] K. Kambly and T. H. Bradley, "Geographical and temporal differences in electric vehicle range due to cabin conditioning energy consumption," Journal of Power Sources, vol. 275, no. 1, pp. 468-475, 2015.

[95] J. Lindgren and P. D. Lund, "Effect of extreme temperatures on battery charging and performance of electric vehicles," Journal of Power Sources, vol. 328, no. 1, pp. 37-45, 2016.

[96] J. Nerling, F. Schaller and O. Arnold, Thermal Pre-conditiong of Electric Vehicles for Range Extension, ATZ 07/08, 2013, pp. 38-42.

[97] M. Al-Zareer, I. Dincer and M. A. Rosen, "Development and analysis of a portable compressed liquid air cooling system for fast vehicle cabin cooling," International Journal of Refrigeration, vol. 84, no. 1, pp. 117 $127,2017$.

[98] H. Pan, L. Qi, X. Zhang, Z. Zhang, W. Salman, Y. Yuan and C. Wang, "A portable renewable solar energy-powered cooling system based on wireless power transfer for a vehicle cabin," Applied Energy, vol. 195, no. 1, pp. 334-343, 2017.

[99] A. Caldevilla, M. Özbek, W. Hünemörder, T. Györög, E. Hougard and M. Pintea, "Efficient cabin and powertrain preconditioning for EVs with a water-to-water heat pump system," in Twelfth International Conference on Ecological Vehicles and Renewable Energies (EVER), Monte Carlo, Monaco, 2017, pp. 1-5.

[100]B. Torregrosa-Jaime, C. Vasile, M. Risser, C. Muller, J. Corberan and J. Payá, "Application of Magnetocaloric Heat Pumps in Mobile AirConditioning," SAE Int. J. Passeng. Cars - Mech. Syst., vol. 6, no. 2, pp. $520-528,2013$

[101]C. Alaoui and Z. M. Salameh, "A novel thermal management for electric and hybrid vehicles," IEEE Transactions on Vehicular Technology, vol. 54, pp. 468-476, 2005.

[102]M. Hosoz and M. Direk, "Performance evaluation of an integrated automotive air conditioning and heat pump system," Energy Conversion and Management, vol. 47, no. 5, pp. 545-559, 2006.

[103]H.-S. Lee and M.-Y. Lee, "Steady state and start-up performance characteristics of air source heat pump for cabin heating in an electric passenger vehicle," International Journal of Refrigeration, vol. 69, no. 1, pp. 232-242, 2016

[104]C.-W. Cho, H.-S. Lee, J.-P. Won and M.-Y. Lee, "Measurement and Evaluation of Heating Performance of Heat Pump Systems Using Wasted Heat from Electric Devices for an Electric Bus," Energies, vol. 5, no. 3, pp. 658-669, 2012

[105]M. Hosoz, M. Direk, K. S. Yigit, M. Canakci, A. Turkcan, E. Alptekin and A. Sanli, "Performance evaluation of an R134a automotive heat pump system for various heat sources in comparison with baseline heating system," Applied Thermal Engineering, vol. 78, no. 1, pp. 419-427, 2015. 
[106]J. H. Ahn, H. Kang, H. S. Lee, H. W. Jung, C. Baek and Y. Kim, "Heating performance characteristics of a dual source heat pump using air and waste heat in electric vehicles," Applied Energy, vol. 119, pp. 1-9, 2014.

[107]G. Zhou, H. Li, E. Liu, B. Li, Y. Yan, T. Chen and X. Chen, "Experimental study on combined defrosting performance of heat pump air conditioning system for pure electric vehicle in low temperature," Applied Thermal Engineering, vol. 116, no. 1, pp. 677-684, 2017.

[108]J. H. Ahn, J. S. Lee, C. Baek and Y. Kim, "Performance improvement of a dehumidifying heat pump using an additional waste heat source in electric vehicles with low occupancy," Energy, vol. 115, no. 1, pp. 67-75, 2016.

[109]J. H. Ahn, H. Kang, H. S. Lee and Y. Kim, "Performance characteristics of a dual-evaporator heat pump system for effective dehumidifying and heating of a cabin in electric vehicles," Applied Energy, vol. 146, no. 1, pp. 29-37, 2015

[110]A. Steiner and R. Rieberer, "Simulation based identification of the ideal defrost start time for a heat pump system for electric vehicles," International Journal of Refrigeration, vol. 57, no. 1, pp. 87-93, 2015.

[111]G. Zhang, H. Zou, F. Qin, Q. Xue and C. Tian, "Investigation on an improved heat pump AC system with the view of return air utilization and anti-fogging for electric vehicles," Applied Thermal Engineering, vol. 115 , no. 1 , pp. $726-735,2017$.

[112]S. Li, S. Wang, Z. Ma, S. Jiang and T. Zhang, "Using an air cycle heat pump system with a turbocharger to supply heating for full electric vehicles," International Journal of Refrigeration, vol. 77, no. 1, pp. 1119, 2017.

[113]C. Arpagaus, F. Bless, J. Schiffmann and S. S. Bertsch, "Multitemperature heat pumps: A literature review," International Journal of Refrigeration, vol. 69, no. 1, pp. 437-465, 2016

[114]S. C. Kim, M. S. Kim, I. C. Hwang and T. W. Lim, "Heating performance enhancement of a $\mathrm{CO} 2$ heat pump system recovering stack exhaust thermal energy in fuel cell vehicles," International Journal of Refrigeration, vol. 30, no. 7, pp. 1215-1226, 2007.

[115]S. C. Kim, M. S. Kim, I. C. Hwang and T. W. Lim, "Performance evaluation of a $\mathrm{CO} 2$ heat pump system for fuel cell vehicles considering the heat exchanger arrangements," International Journal of Refrigeration vol. 30, no. 7, pp. 1195-1206, 2007.

[116]F. Qin, Q. Xue, G. M. Albarracin Velez, G. Zhang, H. Zou and C. Tian, "Experimental investigation on heating performance of heat pump for electric vehicles at $-20^{\circ} \mathrm{C}$ ambient temperature," Energy Conversion and Management, vol. 102, no. 1, pp. 39-49, 2015.

[117]A. Lajunen, T. Hadden, R. Hirmiz, J. Cotton and A. Emadi, "Thermal Energy Storage for Increasing Heating Performance and Efficiency in Electric Vehicles," in IEEE Transportation Electrification Conference and Expo (ITEC'17), Chicago, USA, 2017, pp. 95-100.

[118]Z. Z. Fang, C. Zhou, P. Fan, K. S. Udell, R. C. Bowman, J. J. Vajo, J. J. Purewal and B. Kekelia, "Metal hydrides based high energy density thermal battery," Journal of Alloys and Compounds, vol. 645, no. Supplement 1, pp. S184-S189, 2015.

[119]Q. Zhang and M. Canova, "Mild hybrid technique using the automotive air-conditioning system," Proc IMechE Part D: J Automobile Engineering, vol. 230, no. 10, pp. 1392-1402, 2015.

[120]V. Dreißigacker and S. Belik, "High temperature solid media thermal energy storage system with high effective storage densities for flexible heat supply in electric vehicles," Applied Thermal Engineering, vol. 149 , no. 1, pp. 173-179, 2019.

[121]A. Jokar, S. J. Eckels and M. H. Hosni, "Evaluation of Heat Transfer and Pressure Drop for the Heater-Core in an Automotive Heat Pump System," in ASME International Mechanical Engineering Congress and Exposition, Anaheim, California USA, 2004, pp. 57-65.

[122]H.-T. Chen and J.-C. Chou, "Investigation of natural-convection heat transfer coefficient on a vertical square fin of finned-tube hea exchangers," International Journal of Heat and Mass Transfer, vol. 49, no. 17-18, pp. 3034-3044, 2006.

[123]B. Torregrosa-Jaime, J. M. Corberán, J. Payá and J. L. Delamarche, "Thermal characterisation of compact heat exchangers for air heating and cooling in electric vehicles," Applied Thermal Engineering, vol. 115, no. 1, pp. 774-781, 2017.

[124]M. H. Shojaeefard, G. R. Molaeimanesh, A. Yarmohammadi and S. Changizian, "Multi-objective optimization of an automotive louvered finflat tube condenser for enhancing HVAC system cooling performance," Applied Thermal Engineering, vol. 125, no. 1, pp. 546-558, 2017.

[125]J. Lopez-Sanz, C. Ocampo-Martinez, J. Alvarez-Florez, M. MorenoEguilaz, R. Ruiz-Mansilla, J. Kalmus, M. Gräeber and G. Lux, "Nonlinear Model Predictive Control for Thermal Management in Plug-in Hybrid
Electric Vehicles," IEEE Transactions on Vehicular Technology, vol. 66, no. 5 , pp. 3632-3644, 2017

[126]F. Merz, A. Sciarretta, J.-C. Dabadie and L. Serrano, "On the Optimal Thermal Management of Hybrid-Electric Vehicles with Heat Recovery Systems," Oil and Gas Science and Technology. Institut Francais du Petrole, vol. 67, no. 5, pp. 601-612, 2012.

[127]M. Shams-Zahraei, A. Z. Kouzani, S. Kutter and B. Bäker, "Integrated thermal and energy management of plug-in hybrid electric vehicles," Journal of Power Sources, vol. 216, pp. 237-248, 2012.

[128]J. Gissing, T. Lichius, S. Baltzer, D. Hemkemeyer and L. Eckstein, "Predictive Energy Management of Range-Extended Electric Vehicles Considering Cabin Heat Demand and Acoustics," in 4th IFAC Workshop on Engine and Powertrain Control, Simulation and Modeling E-COSM, Columbus, Ohio, USA, 2015, pp. 209-216.

[129]Y. Huang, A. Khajepour, F. Bagheri and M. Bahrami, "Modelling and optimal energy-saving control of automotive air-conditioning and refrigeration systems," Proc IMechE Part D: J Automobile Engineering, vol. 231, no. 3, pp. 291-309, 2016.

[130]L. Horrein, A. Bouscayrol, Y. Cheng, C. Dumand, G. Colin and Y. Chamaillard, "Influence of the heating system on the fuel consumption of a hybrid electric vehicle," Energy Conversion and Management, vol. 129, no. 1, pp. 250-261, 2016.

[131]S. Twaha, J. Zhu, Y. Yan and B. Li, "A comprehensive review of thermoelectric technology: Materials. applications. modelling and performance improvement," Renewable and Sustainable Energy Reviews, vol. 65 , no. 1 , pp. $698-726,2016$.

[132]M. R. Amini, H. Wang, X. Gong, D. Liao-McPherson, I. Kolmanovsky and J. Sun, "Cabin and Battery Thermal Management of Connected and Automated HEVs for Improved Energy Efficiency Using Hierarchical Model Predictive Control," IEEE Transactions on Control Systems Technology, vol. Early Access, pp. 1-16, 2019.

[133]H. Wang, I. Kolmanovsky, M. R. Amini and J. Sun, "Model Predictive Climate Control of Connected and Automated Vehicles for Improved Energy Efficiency," in Annual American Control Conference (ACC), Milwaukee, WI, USA, 2018, pp. 1-6.

[134]H. Esen, T. Tashiro, D. Bernardini and A. Bemporad, "Cabin heat thermal management in hybrid vehicles using model predictive control," in 22nd Mediterranean Conference on Control and Automation, Palermo, Italy, 2014, pp. 49-54.

[135]N. Wolfe, X. Mu, L. Huang and P. Kadle, "Cooling with Augmented Heated and Cooled Seats," SAE Technical Paper 2007-01-1193, pp. 1-10, 2007.

[136]A. Velivelli, D. Guerithault and S. Stöwe, "Optimum Seat Cooling Distribution for Targeted Human Thermal Comfort," SAE Int. J. Passeng. Cars - Mech. Syst., vol. 10, no. 1, pp. 128-134, 2017.

[137]M. Wang, E. Wolfe, D. Ghosh, J. Bozeman, K.-h. Chen, T. Han, H. Zhang and E. Arens, "Localized Cooling for Human Comfort," SAE Int. J. Passeng. Cars - Mech. Syst., vol. 7, no. 2, pp. 755-768, 2014

[138]M. Wang, D. Ghosh, E. Wolfe, K.-h. Chen and J. Bozeman, "Energy Efficiency Impact of Localized Cooling," SAE Technical Paper 2014-010695, pp. 1-17, 2014.

[139]A. Steiner and A. Mladek, "Reducing the energy consumption for comfort and thermal conditioning in EVs," in Twelfth International Conference on Ecological Vehicles and Renewable Energies (EVER), Monte Carlo, Monaco, 2017, pp. 1-4.

[140]G. J. Marshall, C. P. Mahony, M. J. Rhodes, S. R. Daniewicz, N. Tsolas and S. M. Thompson, "Thermal Management of Vehicle Cabins, External Surfaces, and Onboard Electronics: An Overview," Engineering, vol. 5, no. 5 , pp. 954-969, 2019

[141]H. Zou, W. Wang, G. Zhang, F. Qin, C. Tian and Y. Yan, "Experimental investigation on an integrated thermal management system with heat pipe heat exchanger for electric vehicle," Energy Conversion and Management, vol. 118, no. 1, pp. 88-95, 2016.

[142]S. Shahidinejad, E. Bibeau and S. Filizadeh, "Design and simulation of a thermal management system for plug-in electric vehicles in cold climates," SAE Technical Paper 2012-01-0118, pp. 1-7, 2012.

[143]M. Wang, E. Wolfe, T. Craig, T. J. LaClair, Z. Gao and O. Abdelaziz, "Design and Testing of a Thermal Storage System for Electric Vehicle Cabin Heating," SAE Technical Paper 2016-01-0248, pp. 1-7, 2016.

[144]M. Kolhe, S. K. Adhikari and T. Muneer, "Parked electric car's cabin heat management using photovoltaic powered ventilation system," Applied Energy, vol. 233-234, no. 1, pp. 403-411, 2019. 


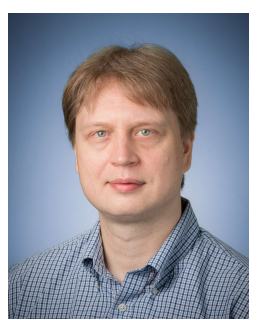

Antti Lajunen (IEEE M'10-SM'18) received the M.Sc. degree in Mechanical Engineering from Helsinki University of Technology, Espoo, Finland, in 2005 and Master of Advanced Studies degree in Industrial Engineering from Ecole Centrale Paris (ECP), Paris, France, in 2007. He received his D.Sc. in 2014 from Aalto University, Espoo, Finland.

$\mathrm{He}$ is currently working as an Assistant Professor in Agricultural Engineering at the University of Helsinki, Finland. From 2016 to 2017, he worked as Post-Doctoral Fellow at McMaster University where his research focused on thermal management of electric vehicles. His other research interests are electrification of agricultural vehicles and machinery, automation in agriculture, and high fidelity modeling of off-road vehicles.

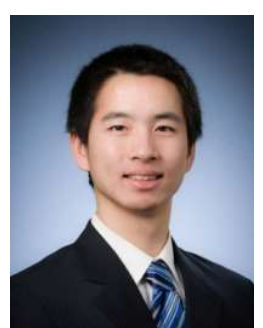

Yinye Yang (IEEE S'11-M14-SM'18) received B.S. degree in Mechanical Engineering from Tsinghua University, China, in 2010, M.S. degree in Mechanical Engineering from University of Illinois at Urbana-Champaign (UIUC), USA, in 2010, and Ph.D. degree in Electrical Engineering from McMaster University, Canada, in 2014.

He worked as a principal research engineer for McMaster University from 2014 to 2015 . He then joined Magna Powertrain since 2015 and has been an adjunct assistant professor with McMaster University since 2016. Dr. Yang is the principal author/co-author of 6 patent applications, 8 book chapters, and numerous journal transaction and international conference papers. He serves as an associate editor for IEEE Transactions on Transportation Electrification and a regular reviewer for multiple IEEE, IET, MPDI Transactions and journals. He also serves as committee chair for IEEE Transportation Electrification Conference and Expo (ITEC) and session chair in multiple international conferences.

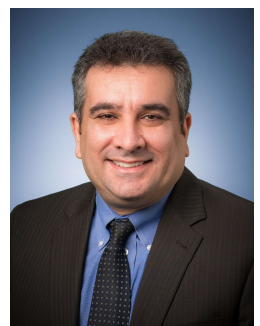

Ali Emadi (IEEE S'98-M'00-SM'03-F'13) received the B.S. and M.S. degrees in electrical engineering with highest distinction from Sharif University of Technology, Tehran, Iran, in 1995 and 1997, respectively, and the Ph.D. degree in electrical engineering from Texas A\&M University, College Station, TX, USA, in 2000. $\mathrm{He}$ is the Canada Excellence Research Chair in Hybrid Powertrain at McMaster University in Hamilton, Ontario, Canada. Before joining McMaster University, Dr. Emadi was the Harris Perlstein Endowed Chair Professor of Engineering and Director of the Electric Power and Power Electronics Center and Grainger Laboratories at Illinois Institute of Technology in Chicago, Illinois, USA, where he established research and teaching facilities as well as courses in power electronics, motor drives, and vehicular power systems. He was the Founder, Chairman, and President of Hybrid Electric Vehicle Technologies, Inc. (HEVT) - a university spin-off company of Illinois Tech. Dr. Emadi has been the recipient of numerous awards and recognitions. He was the advisor for the Formula Hybrid Teams at Illinois Tech and McMaster University, which won the GM Best Engineered Hybrid System Award at the 2010, 2013, and 2015 competitions. He is the principal author/coauthor of over 400 journal and conference papers as well as several books including Vehicular Electric Power Systems (2003), Energy Efficient Electric Motors (2004), Uninterruptible Power Supplies and Active Filters (2004), Modern Electric, Hybrid Electric, and Fuel Cell Vehicles (2nd ed, 2009), and Integrated Power Electronic Converters and Digital
Control (2009). He is also the editor of the Handbook of Automotive Power Electronics and Motor Drives (2005) and Advanced Electric Drive Vehicles (2014). Dr. Emadi was the Inaugural General Chair of the 2012 IEEE Transportation Electrification Conference and Expo (ITEC) and has chaired several IEEE and SAE conferences in the areas of vehicle power and propulsion. He is the founding Editor-in-Chief of the IEEE Transactions on Transportation Electrification. 